\title{
THE STRUCTURAL AND FUNCTIONAL ASPECTS OF THE HANDLING OF GLUCOSE BY THE NEPHRONS AND THE KIDNEY AND THEIR CORRELATION BY MEANS OF STRUCTURAL-FUNCTIONAL EQUIVALENTS *
}

\author{
By JEAN OLIVER AND MURIEL MACDOWELL
}

(From the Renal Research Unit, the Research Department, CIBA Pharmaceutical Products Inc., Summit, N.J.)

(Submitted for publication November 18, 1960 ; accepted March 2, 1961)

\section{INTRODUCTION}

Since the value of any correlative procedure obviously depends upon the quantitative and statistical validity of each of its individual correlates, error in one term invalidating the whole, it is understandable that attempts to relate structural with functional data in the area of renal activity remain in great part unconvincing. The structural data that have been used in such correlations are in most instances purely descriptive and qualitative in nature, often at best an opinion of the observer, while the functional terms of the correlation, though valid in their quantitative expression, are, from the indirection of their approach to the localization of renal activity, open to a considerable variance in interpretation. ${ }^{1}$

In one restricted field of mammalian renal physiology, these criticisms have been answered by the use of the direct methods of observation afforded by microdissection and micropuncture (1). By the former, the nephrons have been isolated in their natural continuity, puncture points identified and measurements made of their various dimensions; by the latter it has been observed that glucose passes through the glomerular filter in the same concentration that obtains in the blood and that it disappears from the fluid in the lumen of the proximal convolution in an evenly falling gradient; reabsorption is largely completed at the midpoint of this segment (2) so that no other portions of the nephron are concerned in the process.

* This work was supported by Grant $\mathrm{H}-3765-\mathrm{C} 1$ from the National Heart Institute, Bethesda, Md.

1 A more general consideration of the problems of structural-functional correlations and a suggested resolution of the antithesis, Structure-Function, based on the present work, will be found in the Middleton Goldsmith Lecture, Bull. N. Y. Acad. Med. 1961, 2nd ser., 37, 81.
On the basis of this definitive knowledge of how glucose is handled by the mammalian nephron, and the observations of Shannon and Fisher (3) on what occurs in the kidney of the dog during the saturation of the reabsorptive capacity of its tubules, Smith, Goldring, Chasis, Ranges and Bradley (4) have examined by means of urine/ plasma ratios the same problem as it is observed in the kidney of man and, from a theoretical analysis of the situation, have arrived at a functional "titration" in which the distribution of activity among the constituent nephrons is described.

Not only is a quantitative expression of the dispersion of functional activity among the nephrons in the normal human kidney thus obtained, but certain details of the process of tubular saturation become apparent which are of importance in the interpretation of its mechanism; in particular, the rising line of the curve that represents this tubular activity in the kidney does not break abruptly at a point of complete tubular saturation but shows a gradual inflexion to the horizontal level of maximal reabsorption.

The occurrence of this splay in the curve has raised a fundamental question regarding its cause. According to the interpretation of Smith and co-workers (4), the splay is due to variation in the activity of the individual glomeruli and tubules concerned in the over-all process. Opposed to this view is the belief, held in a recent review to be "overwhelmingly" more probable by Mudge (5), that the splay results from kinetic factors that can be described by the Menten-Michaelis formulation of the enzyme reaction rates which are responsible for the transport of glucose across the tubule wall (6).

The second of these hypotheses has been examined by Burgen (7) who, assuming equality of activity in all nephrons of the kidney and sub- 
TABLE I

Description of dissected kidneys

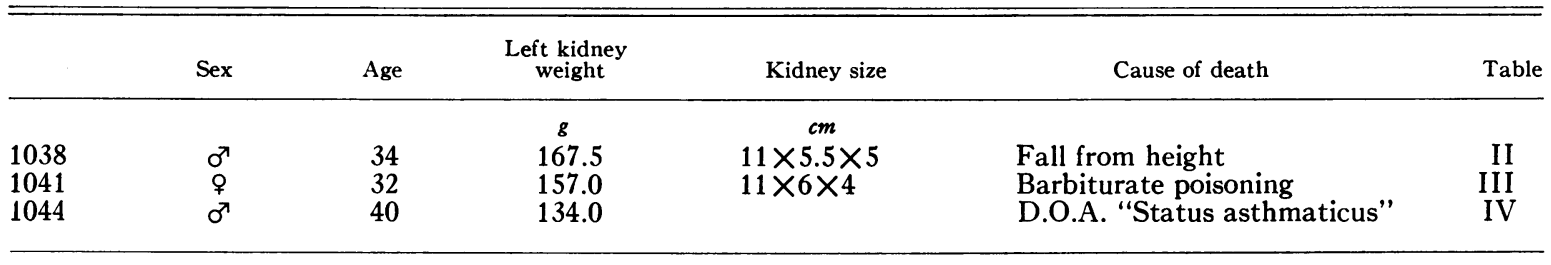

stituting varying affinity constants in the MentenMichaelis formula for the transport of glucose, finds that the resulting theoretical curves do not correspond with similar representations derived from the observed data of Smith and colleagues (4). He concludes that the departure from ideal behavior of the curve of glucose saturation in man cannot therefore be attributed to a kinetic variation in saturation of a transport system and that the source of the observed splay must be due to a statistical dispersion of some other "undetermined tubule characteristics" in the kidney.

The failure of the kinetic formula to describe the course of tubular saturation directs attention back to the first and simpler hypothesis, as expressed by Govaerts (8), that variations in the physical "size, shape and relations" of the functioning components, the nephrons, may be the characteristics that determine the curve of functional activity observed in the kidney qua kidney; the present study examines this possibility. ${ }^{2}$

The general aspects of this correlation of structure and function will first be examined in the case of the normal human kidney by comparing currently available functional measurements $(4,9)$ with new structural data obtained by microdissection and measurement of the componentsglomeruli and proximal convolutions-which micropuncture has shown to be the only participants in the filtration and reabsorption of glucose. An analysis of these quantitative and statistically adequate structural data will then determine the selection of appropriate correlates with the functional data and certain structural-functional equivalents will be established. With these equivalents it should be possible to derive the commonly used functional expressions, maximal tubular reabsorption of glucose $\left(\mathrm{Tm}_{G}\right)$, glomerular filtration rate

2 A preliminary survey of this problem appeared in the Livre Jubilaire de Prof. Paul Govaerts, Brussels, 1955, p. 1.
(GFR), and $\mathrm{Tm}_{\mathrm{G}} / \mathrm{GFR}$, and to reconstruct the glucose titration curve with its typical splay from the data of the structural measurements.

\section{STRUCTURAL PROLEGOMENA FOR FUNCTIONAL CORRELATIONS IN THE KIDNEY}

\section{Material and methods}

The material consisted of the left kidney from three young adults, two male and one female, who had died by accident; the tissues were preserved in 10 per cent formalin (Table I).

At the autopsies no complicating lesions were found that could be presumed to have affected the kidneys. All the kidneys were normal in shape, with smooth surfaces; several microscopic sections from each showed no scars, tubular changes or other evidence of a departure from normal relations. The calculated weight for two kidneys is 335,314 , and $268 \mathrm{~g}$, and their mean, $305 \mathrm{~g}$, lies between the figure given by Thoma, $328 \mathrm{~g}$ (10) for individuals of this age group, and that of Roessle and Roulet, $287 \mathrm{~g}$ (11).

The general procedure of microdissection has been previously described (12). Small blocks of tissue, measuring approximately $1.0 \times 2.0 \times 0.3 \mathrm{~cm}$, which included all of the cortex and the greater part or all of the medulla, were excised from each kidney in such manner as to give a general distribution over its external surface Each was placed in concentrated $\mathrm{HCl}$ until properly macerated, a period which varied with different specimens from 40 to 48 hours. After thorough rinsing by decantation in tap water, the entire softened mass, suspended in a glass dish of water, was separated with needles under the binocular microscope until the outlines of the individual nephrons were revealed. From each preparation 6 to 8 complete proximal convolutions with their attached glomeruli were then isolated by random selection; 2 were taken from beneath the capsular surface of the kidney, 2 from mid-cortex and 2 from its lowermost layer. The isolated nephron was then floated onto a slide with a few drops of water. Two thick streaks of Vaseline had been placed along the edges of the slide so that when a coverglass was placed upon them it did not compress the unstained specimen but formed a cell which contained it, when the remaining free edges were sealed with Vaseline.

The maceration and dissection had been so performed that the tightly coiled convolutions of the tubule, which, 
as they lie in the kidney, form a globular packet around their glomerulus (Reference 1, Figures 5-10), were widely opened but not completely straightened; in this way its course could be followed for measurement without error due to either foreshortening as the tubule bent sharply toward or away from the observer, or to stretching by the tension which would have been required to straighten its coils completely.

Camera lucida tracings at a magnification of $42 \times$ were then made of the glomerulus and its attached proximal convolution, and the length of the tubule was measured by following the course of its midline with a mapmeasure. The diameter of the convolution was measured directly on the original specimen with a filar micrometer at a magnification of $50 \times$. Ten measurements of each convolution distributed evenly along its course were averaged for the final figure; the volume was then calculated as that of a cylinder. Inspection shows that there is no patent tubule lumen in the fixed specimen of proximal convolution so that the calculation may be taken as representing the volume of its tubular cells.

The greatest and least external diameters of the glomeruli, including their closely contiguous capsular membranes, were also measured in the original specimen with the micrometer, averaged, and surface and volume calculated as that of a sphere. Further discussion of the validity of these necessary simplifications in measurement and calculation will be considered later (p. 1101).

Especial care was taken to avoid errors in measurement due to swelling of the macerating tissues or the final mounted specimen. As Sperber (13) points out, swelling or shrinkage may result from variation in acidity, temperature and the passage of time during the manipulations from maceration to final measurement; we would emphasize the importance of the last two factors.

To control them, maceration was done in a constant temperature cabinet at $65^{\circ} \mathrm{F}$ for the constant period which had been found most suitable for the tissues of the par-

TABLE II

Dimensions of Glomerulus and Proximal Convolution

I 2038 of K1dney Welght 355 gms.

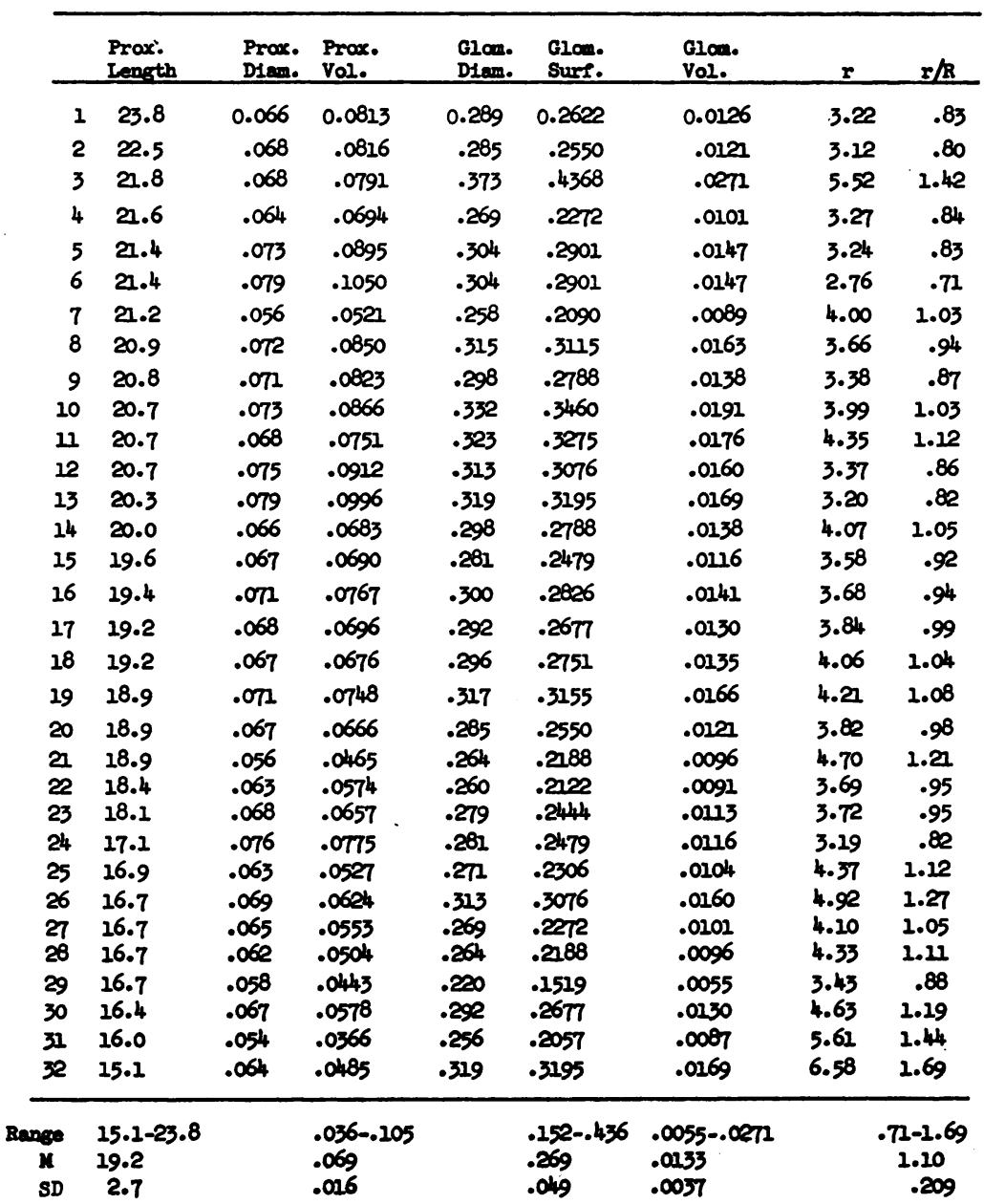


TABIE III

Dimensions of Glonesulus and Proximal Convolution

II 1041 \& Kidney Weight 157 gms

\begin{tabular}{|c|c|c|c|c|c|c|c|c|}
\hline & $\begin{array}{l}\text { Prox. } \\
\text { Length }\end{array}$ & $\begin{array}{l}\text { Prox. } \\
\text { Dien. }\end{array}$ & $\begin{array}{l}\text { Prox. } \\
\text { Vol. }\end{array}$ & $\begin{array}{l}\text { Olom. } \\
\text { Dlan. }\end{array}$ & $\begin{array}{l}\text { Glow. } \\
\text { Surf. }\end{array}$ & $\begin{array}{l}\text { Glom. } \\
\text { Vol. }\end{array}$ & $\underline{r}$ & $r / R$ \\
\hline 1 & 25.6 & 0.080 & 0.1286 & 0.285 & 0.2550 & 0.0121 & 1.98 & .77 \\
\hline 2 & 25.4 & .072 & .1033 & .262 & .2255 & .0094 & 2.08 & .81 \\
\hline 3 & 25.2 & .069 & .00442 & .249 & .1946 & .0080 & 2.06 & .80 \\
\hline 4 & 24.9 & .076 & .1128 & .332 & .3460 & .0191 & 3.06 & 1.19 \\
\hline 5 & 24.7 & .071 & .0977 & .241 & .1823 & .0073 & 1.86 & .72 \\
\hline 6 & 24.5 & .073 & .1025 & .251 & .1978 & .0082 & 1.92 & .75 \\
\hline 7 & 23.6 & .066 & .0806 & .266 & .2221 & .0098 & 2.75 & 1.07 \\
\hline 8 & 23.0 & .072 & .0936 & .261 & .2138 & .0093 & 2.28 & .89 \\
\hline 9 & 22.3 & .070 & .0857 & .246 & .1900 & .0077 & 2.21 & .86 \\
\hline 10 & 21.8 & .075 & .0961 & .277 & .2409 & .0111 & 2.50 & .97 \\
\hline 11 & 20.7 & .062 & .0625 & .298 & .2788 & .0138 & 4.45 & 1.74 \\
\hline 12 & 20.7 & .069 & .0773 & .245 & .1884 & .0077 & 2.43 & .95 \\
\hline 13 & 20.7 & .075 & .0912 & .258 & .2090 & .0089 & 2.28 & .89 \\
\hline 14 & 20.7 & .072 & .0842 & .242 & .1838 & .0074 & 2.18 & .85 \\
\hline 15 & 20.6 & .072 & .0838 & .243 & .1854 & .0075 & 2.21 & .86 \\
\hline 16 & 20.4 & .072 & .0830 & .261 & .2138 & .0093 & 2.57 & 1.00 \\
\hline 17 & 20.4 & .067 & .0719 & .250 & .1962 & .0081 & 2.72 & $i .06$ \\
\hline 18 & 20.4 & .068 & .0740 & .225 & .1589 & .0059 & 2.14 & .83 \\
\hline 19 & 20.2 & .072 & .0822 & .276 & .2391 & .0110 & 2.90 & 1.13 \\
\hline 20 & 20.2 & .069 & .0755 & .241 & .1823 & .0073 & 2.41 & . 94 \\
\hline 21 & 19.7 & .076 & .0893 & .264 & .2188 & .0096 & 2.45 & .95 \\
\hline 22 & 19.7 & .067 & .0694 & .256 & .2057 & .0087 & 2.96 & 1.15 \\
\hline 23 & 19.7 & .069 & .0736 & .248 & .1931 & .0079 & 2.62 & 1.02 \\
\hline 24 & 19.4 & .077 & .0904 & .292 & .2677 & .0130 & 2.96 & 1.15 \\
\hline 25 & 19.3 & .067 & .0680 & .230 & .1661 & .0063 & 2.44 & .95 \\
\hline 26 & 19.2 & .075 & .0846 & .272 & .2323 & .0105 & 2.74 & 1.07 \\
\hline 27 & 18.6 & .077 & .0866 & .234 & .1719 & .0067 & 1.98 & .77 \\
\hline 28 & 18.5 & .067 & .0652 & .229 & .1646 & .0062 & 2.52 & .98 \\
\hline 29 & 18.3 & .074 & .0786 & .258 & .2090 & .0089 & 2.65 & 1.03 \\
\hline 30 & 18.1 & .070 & .0696 & .247 & . 1915 & .0078 & 2.75 & 1.07 \\
\hline 31 & 17.8 & .067 & .0627 & .230 & .1661 & .0063 & 2.64 & 1.03 \\
\hline 32 & 17.6 & .073 & .0736 & .252 & .1994 & .0083 & 2.70 & 1.05 \\
\hline 33 & 17.6 & .070 & .0677 & .261 & .2138 & .0093 & 3.15 & 1.23 \\
\hline 34 & 17.6 & .071 & .0696 & .247 & .1915 & .0078 & 2.74 & 1.07 \\
\hline 35 & 16.0 & .070 & .0615 & .233 & .1704 & .0066 & 2.76 & 1.08 \\
\hline 36 & 16.0 & .064 & .0514 & .208 & .1358 & .00147 & 2.64 & 1.03 \\
\hline 37 & 15.9 & .070 & .0611 & .238 & .1778 & .0070 & 2.90 & 1.13 \\
\hline 38 & 15.9 & .064 & .0511 & .223 & .1561 & .0058 & 3.05 & 1.19 \\
\hline 39 & 15.9 & .068 & .0577 & .220 & .1519 & .0055 & 2.63 & 1.02 \\
\hline 40 & 14.7 & .062 & .0444 & .216 & .1464 & .0052 & 3.29 & 1.28 \\
\hline 41 & 13.6 & .066 & .0464 & .231 & .1675 & .0064 & 3.60 & 1.40 \\
\hline 42 & 13.4 & .057 & .0341 & .180 & .1017 & .0030 & 2.97 & 1.16 \\
\hline & $13.4-25.6$ & & $.034-.128$ & & $.101-.346$ & $.0030-.0191$ & & $.72-1.74$ \\
\hline $\mathbf{x}$ & 19.7 & & .077 & & .197 & .0083 & & 1.02 \\
\hline$S D$ & 3.31 & & .016 & & .039 & .0026 & & .188 \\
\hline
\end{tabular}

ticular kidney under examination. An optimal maceration produced tubules that could be isolated with the needle but which retained a certain degree of their original elasticity. The dissection and measurement were completed promptly after maceration, usually the same day, in an air-conditioned laboratory at $70^{\circ} \mathrm{F}$, or, if within 24 hours, the preparation was stored in the icebox overnight.

Under these conditions, swelling or shrinkage was not a disturbing factor as was evident from the reproduci- 
bility of the measurements of both glomeruli and tubules from the same kidney; this became apparent since our study extended over more than a year. A few examples were macerated, dissected and measured on different occasions; the consolidated results were found to give statistically consistent data.

\section{The dimensions of proximal convolutions and glomeruli}

The measurements from the three individual kidneys are given in Tables II-IV; since these measurements will be used later in correlation with the functional data of Smith and co-workers $(4,9)$ which combine measurements made on several individuals, they also appear in Table $\mathrm{V}$ in consolidated form along with certain calculated derivatives that will be used in the correlative process. The four dimensions, length and volume of proximal convolutions, and surface and volume of the glomeruli, appear in graphic form along with statistical data in Figures 1-4.

Comment. The figure commonly quoted for the length of the human proximal convolution, $15.0 \mathrm{~mm}$, is based on Peter's (14) measurements of 5 nephrons from 3 individuals of unknown age; Pai (15), measuring 9 nephrons from 3 young men found a mean length of $20.1 \mathrm{~mm}$. The glomerular measurements of the two investigators differ even more, the diameters being, respectively,

TABIE IV

Dimenglons of Glomerolus and Proximal Convolution

III 1044 of KIdney Weight 268 gans.

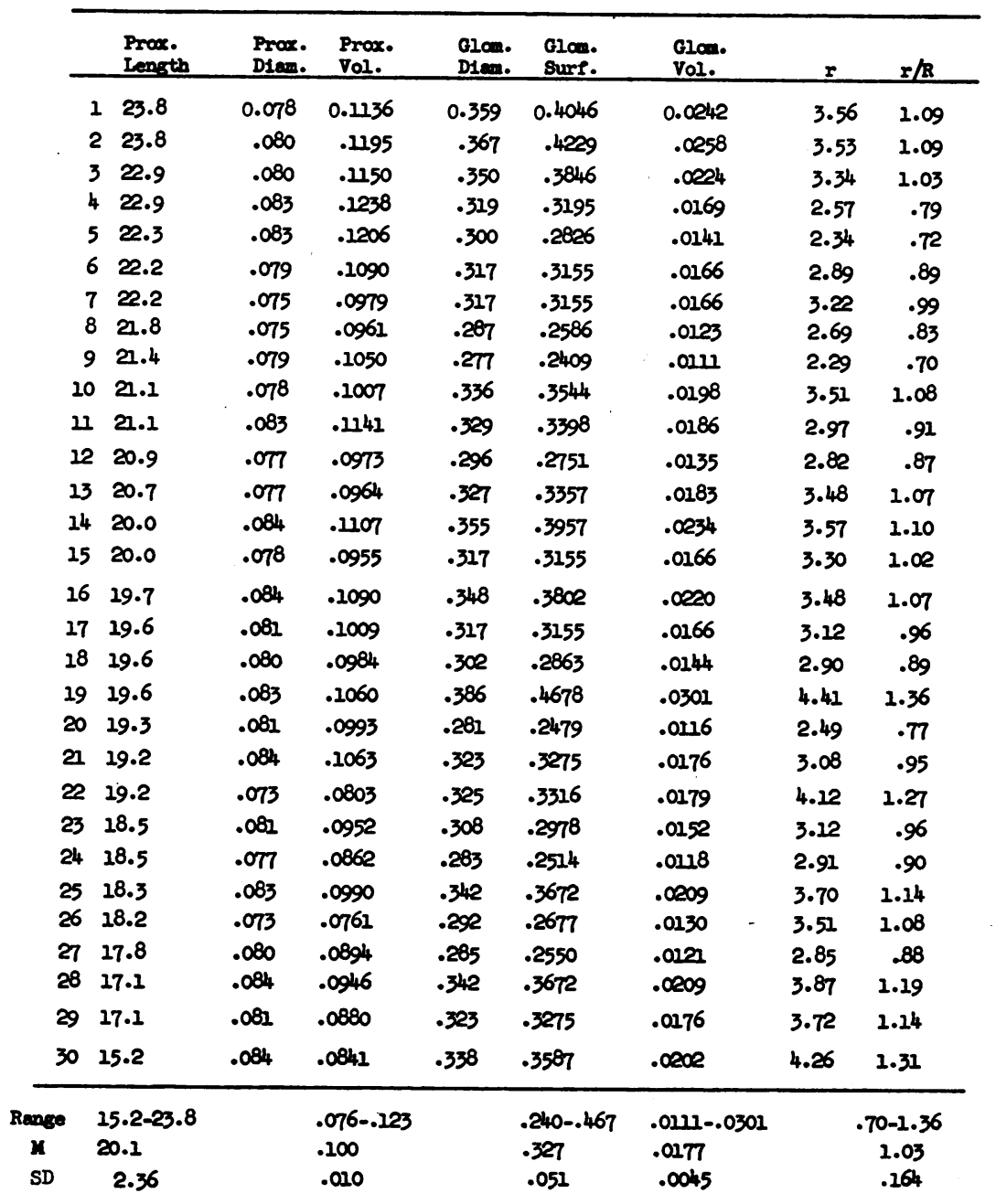


TABIE V

Dimensions of Glonerulus end Proximal Convolution

I 1038 of Kidney Weight 355 ens.

II 1041 \& Tidney Welght 314 ens.

III 1044 of Kidney Weicht 268

\begin{tabular}{|c|c|c|c|c|c|c|c|c|c|}
\hline & & $\begin{array}{l}\text { Prox. } \\
\text { Iength }\end{array}$ & $\begin{array}{l}\text { Prax. } \\
\text { Diam. }\end{array}$ & $\begin{array}{l}\text { Prox. } \\
\text { Vol. }\end{array}$ & $\begin{array}{l}\text { Glom. } \\
\text { Diam. }\end{array}$ & $\begin{array}{l}\text { Glom. } \\
\text { Surf. }\end{array}$ & $\begin{array}{l}\text { Glom. } \\
\text { Vol. }\end{array}$ & $r$ & $r / R$ \\
\hline $\begin{array}{l}1 \\
2\end{array}$ & II & $\begin{array}{l}25.6 \\
25.4\end{array}$ & $\begin{array}{r}0.080 \\
.072\end{array}$ & $\begin{array}{r}0.1286 \\
.1033\end{array}$ & $\begin{array}{r}0.285 \\
.262\end{array}$ & $\begin{array}{r}0.2550 \\
.2155\end{array}$ & $\begin{array}{r}0.0121 \\
.00944\end{array}$ & $\begin{array}{l}1.98 \\
2.08\end{array}$ & $\begin{array}{l}.63 \\
.66\end{array}$ \\
\hline 3 & II & 25.2 & .069 & .0942 & .249 & .1946 & .0080 & 2.06 & .65 \\
\hline 4 & II & 24.9 & .076 & .1128 & .332 & . 3460 & .0191 & 3.06 & .97 \\
\hline 5 & II & 24.7 & .071 & .0977 & .241 & .1823 & .0073 & 1.86 & .59 \\
\hline 6 & II & 24.5 & .073 & .1025 & .251 & .1978 & .0082 & 1.92 & .61 \\
\hline 7 & III & 23.8 & .078 & .1136 & .359 & .4046 & .0242 & 3.56 & 1.13 \\
\hline $\begin{array}{l}8 \\
9\end{array}$ & III & $\begin{array}{l}23.8 \\
23.8\end{array}$ & $\begin{array}{l}.080 \\
.066\end{array}$ & .1195 & $\begin{array}{l}.367 \\
.289\end{array}$ & $\begin{array}{l}.4229 \\
.2622\end{array}$ & $\begin{array}{l}.0258 \\
.0126\end{array}$ & $\begin{array}{l}3.53 \\
3.22\end{array}$ & $\begin{array}{l}1.12 \\
1.02\end{array}$ \\
\hline 10 & II & 23.6 & .066 & .0806 & .266 & .2221 & .0098 & 2.75 & .87 \\
\hline 11 & II & 23.0 & .072 & .0936 & .261 & .2138 & .0093 & 2.28 & .72 \\
\hline 12 & III & 22.9 & .080 & . 1150 & .350 & .3846 & .02024 & 3.34 & 1.06 \\
\hline 13 & III & 22.9 & .083 & .1238 & .319 & . 3195 & .0169 & 2.57 & .82 \\
\hline 14 & $I$ & 22.5 & .068 & .0816 & .285 & .2550 & .0121 & 3.12 & .99 \\
\hline 15 & III & 22.3 & .083 & .1206 & .300 & .2026 & .0141 & 2.34 & .74 \\
\hline 16 & III & 22.3 & .070 & .0857 & .246 & .1900 & .0077 & 2.21 & .70 \\
\hline 17 & III & 22.2 & .079 & .1090 & .317 & .3155 & .0166 & 2.89 & .92 \\
\hline 18 & IIII & 22.2 & .075 & .0979 & .317 & .3155 & .0166 & 3.22 & 1.02 \\
\hline 19 & II & 21.8 & .075 & .0961 & .277 & .2409 & 11201. & 2.50 & .79 \\
\hline 20 & III & 21.8 & .075 & .0961 & .287 & .2586 & .0123 & 2.69 & .85 \\
\hline 21 & $I$ & 21.8 & .068 & .0791 & .373 & .4368 & .027 & 5.52 & 1.75 \\
\hline 22 & $I$ & 21.6 & .064 & .0694 & .269 & .2272 & .0101 & 3.27 & 1.04 \\
\hline 23 & III & 21.4 & .079 & .1050 & .277 & .2409 & 11101. & 2.29 & .73 \\
\hline 24 & $I$ & 21.4 & .073 & .0895 & .304 & .2901 & .0147 & 3.24 & 1.03 \\
\hline 25 & $I$ & 21.4 & .079 & .1050 & .304 & .2901 & .0147 & 2.76 & .87 \\
\hline 26 & $I$ & 21.2 & .056 & .0521 & .258 & .2090 & .0089 & 4.00 & 1.27 \\
\hline 27 & III & 21.1 & .078 & .1007 & .336 & .3544 & .0198 & 3.51 & 1.11 \\
\hline 28 & III & 21.1 & .083 & . 2241 & .329 & .3398 & .0186 & 2.97 & .94 \\
\hline 29 & III & 20.9 & .077 & .0973 & .296 & .2751 & .0135 & 2.82 & .89 \\
\hline 30 & $I$ & 20.9 & .072 & .0850 & .315 & .31215 & .0163 & 3.66 & 1.16 \\
\hline 31 & I & 20.8 & .071 & .0823 & .298 & .2788 & .0138 & 3.38 & 1.07 \\
\hline 32 & III & 20.7 & .062 & .0625 & .298 & .2788 & .0138 & 4.45 & 1.41 \\
\hline 33 & II & 20.7 & .069 & .0773 & .245 & .1884 & .0077 & 2.43 & .77 \\
\hline 34 & II & 20.7 & .075 & .0912 & .258 & .2090 & .0089 & 2.28 & .72 \\
\hline 35 & II & 20.7 & .072 & .0842 & .242 & .1838 & .0074 & 2.18 & .69 \\
\hline 36 & III & 20.7 & .077 & .0964 & .327 & $\cdot 3357$ & .0183 & 3.48 & 1.10 \\
\hline 37 & $I$ & 20.7 & .073 & .0866 & .332 & .3460 & .0191 & 3.99 & 1.27 \\
\hline 38 & $I$ & 20.7 & .068 & .0751 & .323 & .3275 & .0176 & 4.35 & 1.38 \\
\hline 39 & $I$ & 20.7 & .075 & .0912 & .313 & .3076 & .0160 & 3.37 & 1.07 \\
\hline 40 & II & 20.6 & .072 & .0838 & .243 & .1854 & .0075 & 2.21 & .70 \\
\hline 41 & II & 20.4 & .072 & .0830 & .261 & .2138 & .0093 & 2.57 & .81 \\
\hline 42 & II & 20.4 & .067 & .0719 & .250 & .1962 & .0081 & 2.72 & .86 \\
\hline 43 & II & 20.4 & .068 & .0740 & .225 & .1589 & .0059 & 2.14 & .68 \\
\hline 44 & $I$ & 20.3 & .079 & .0996 & .319 & .3195 & .0169 & 3.20 & 1.01 \\
\hline 45 & II & 20.2 & .072 & .0022 & .276 & .2391 & .0110 & 2.90 & .92 \\
\hline 46 & II & 20.2 & .069 & .0755 & .241 & .1823 & .0073 & 2.41 & .76 \\
\hline 47 & III & 20.0 & .084 & .1207 & .355 & .3957 & .0234 & 3.57 & 1.13 \\
\hline 48 & III & 20.0 & .078 & .0955 & .317 & .3155 & .0166 & 3.30 & 1.05 \\
\hline 49 & $I$ & 20.0 & .066 & .0683 & .298 & .2788 & .0138 & 4.07 & 1.29 \\
\hline 50 & II & 19.7 & .076 & .0893 & .264 & .2188 & .0096 & 2.45 & .78 \\
\hline 51 & II & 29.7 & .067 & .0694 & .256 & .2057 & .0087 & 2.96 & .94 \\
\hline 52 & II & 19.7 & .069 & .0736 & .248 & . 1931 & .0079 & 2.62 & .83 \\
\hline
\end{tabular}




\begin{tabular}{|c|c|c|c|c|c|c|c|c|c|}
\hline 53 & III & 19.7 & .084 & .1090 & .348 & .3802 & .0220 & 3.48 & 1.10 \\
\hline 54 & III & 19.6 & .081 & .1009 & .317 & .3155 & .0166 & 3.12 & .99 \\
\hline 55 & III & 19.6 & .080 & .0984 & .302 & .2863 & .0144 & 2.90 & .92 \\
\hline 56 & III & 19.6 & .083 & .1060 & .386 & .4678 & .0301 & 4.41 & 1.40 \\
\hline 57 & I & 19.6 & .067 & .0690 & .261 & .2479 & .0116 & 3.58 & 1.14 \\
\hline 58 & I & 19.4 & .071 & .0767 & .300 & .2826 & .0141 & 3.68 & 2.17 \\
\hline 59 & II & 19.4 & .077 & .0904 & .292 & .2677 & .0130 & 2.96 & . 94 \\
\hline 60 & II & 19.3 & .067 & .0680 & .230 & .1661 & .0063 & 2.44 & $\cdot 77$ \\
\hline 61 & III & 19.3 & .081 & .0993 & .281 & .2479 & .0116 & 2.49 & .79 \\
\hline 62 & II & 19.2 & .075 & .0846 & .272 & .2323 & .0105 & 2.74 & .87 \\
\hline $\begin{array}{l}63 \\
64\end{array}$ & IIII & $\begin{array}{l}19.2 \\
19.2\end{array}$ & $\begin{array}{l}.084 \\
.073\end{array}$ & $\begin{array}{l}.1063 \\
.0803\end{array}$ & $\begin{array}{l}.323 \\
.325\end{array}$ & $\begin{array}{l}.3275 \\
.3316\end{array}$ & $\begin{array}{l}.0276 \\
.0179\end{array}$ & $\begin{array}{l}3.08 \\
4.12\end{array}$ & $\begin{array}{r}.98 \\
1.31\end{array}$ \\
\hline 65 & $I$ & 19.2 & .068 & .0696 & .292 & .2677 & .0130 & 3.84 & 1.22 \\
\hline 66 & $I$ & 19.2 & .067 & .0676 & .296 & .2751 & .0135 & 4.06 & 1.29 \\
\hline 67 & $I$ & 18.9 & .071 & .0748 & .317 & .3155 & .0266 & 4.21 & 1.34 \\
\hline 68 & $I$ & 18.9 & .067 & .0666 & .285 & .2550 & .0121 & 3.82 & 1.21 \\
\hline 69 & I & 18.9 & .056 & .0465 & .264 & .2188 & .0096 & 4.70 & 1.49 \\
\hline 70 & II & 18.6 & .077 & .0866 & .234 & .1719 & .0067 & 1.98 & .63 \\
\hline$\pi$ & II & 18.5 & .067 & .0652 & .229 & .1646 & .0062 & 2.52 & .80 \\
\hline 72 & III & 18.5 & .081 & .0952 & .308 & .2978 & .0152 & 3.12 & .99 \\
\hline 73 & III & 18.5 & .077 & .0862 & .283 & .2514 & .0218 & 2.91 & .92 \\
\hline 74 & $I$ & 18.4 & .063 & .0574 & .260 & .2122 & .0091 & 3.69 & 1.17 \\
\hline 75 & II & 18.3 & .074 & .0786 & .258 & .2090 & .0089 & 2.65 & .84 \\
\hline 76 & IIII & 18.3 & .083 & .0990 & .342 & .3672 & .0209 & 3.70 & 1.17 \\
\hline 77 & III & 18.2 & .073 & .0761 & .292 & .2677 & .0130 & 3.51 & 1.11 \\
\hline 78 & II & 18.1 & .070 & .0696 & .247 & .1915 & .0078 & 2.75 & .87 \\
\hline 79 & $I$ & 18.1 & .068 & .0657 & .279 & .2444 & .0113 & 3.72 & 1.18 \\
\hline 80 & III & 17.8 & .080 & .0894 & .285 & .2550 & .0121 & 2.85 & .90 \\
\hline 81 & II & 17.8 & .067 & .0627 & .230 & .1661 & .0063 & 2.64 & .84 \\
\hline $8 \dot{2}$ & II & 17.6 & .073 & .0736 & .252 & .1994 & .0083 & 2.70 & .86 \\
\hline 83 & II & 17.6 & .070 & .0677 & .261 & .2138 & .0093 & 3.15 & 1.00 \\
\hline 84 & II & 17.6 & .077 & .0696 & .247 & .1915 & .0078 & 2.74 & .87 \\
\hline 85 & III & 17.1 & .084 & .0946 & $\cdot 342$ & .3672 & .0209 & 3.87 & 1.23 \\
\hline 86 & III & $17 \cdot 1$ & .081 & .0880 & .323 & .3275 & .0176 & 3.72 & 1.18 \\
\hline 87 & I & 17.1 & .076 & .0775 & .281 & .2479 & .0116 & 3.19 & 1.01 \\
\hline 88 & I & 16.9 & .063 & .0527 & .271 & .2306 & .0104 & 4.37 & 1.39 \\
\hline 89 & $I$ & 16.7 & .069 & .0624 & .313 & .3076 & .0160 & 4.92 & 1.56 \\
\hline 90 & I & 16.7 & .065 & .0553 & .269 & .2272 & .0101 & 4.10 & 1.30 \\
\hline 91 & I & 16.7 & .062 & .0504 & .264 & .2188 & .0096 & 4.33 & 1.37 \\
\hline 92 & I & 16.7 & .058 & .0443 & .220 & .1519 & .0055 & 3.43 & 1.09 \\
\hline 93 & I & 16.4 & .067 & $.057^{8}$ & $: 292$ & .2677 & .0130 & 4.63 & 1.47 \\
\hline 94 & $I$ & 16.0 & .054 & .0366 & .256 & .2057 & .0087 & 5.61 & $1.7^{8}$ \\
\hline 95 & II & 16.0 & .070 & .0615 & .233 & .1704 & .0066 & 2.76 & .87 \\
\hline 96 & II & 16.0 & .064 & .0514 & .208 & .1358 & .0047 & 2.64 & .84 \\
\hline 97 & II & 15.9 & .070 & .0611 & .238 & $.177^{8}$ & .0070 & 2.90 & .92 \\
\hline 98 & II & 15.9 & .064 & .0511 & .223 & .1561 & .0058 & 3.05 & .97 \\
\hline 99 & II & 15.9 & .068 & .0577 & .220 & .1519 & .0055 & 2.63 & .83 \\
\hline 100 & III & 15.2 & .084 & .0841 & .338 & .3507 & .0202 & 4.26 & 1.35 \\
\hline 101 & I & 15.1 & .064 & .0485 & $\cdot 319$ & .3195 & .0169 & 6.58 & 2.09 \\
\hline 102 & II & 24.7 & .062 & .0444 & .216 & .1464 & .0052 & 3.29 & 1.04 \\
\hline 103 & II & 13.6 & .066 & .0464 & .231 & .1675 & .0064 & 3.60 & 1.14 \\
\hline 104 & II & 13.4 & .057 & .0341 & .180 & .1017 & .0030 & 2.97 & .94 \\
\hline & $\mathbf{R}$ & $\begin{array}{r}13.4- \\
25.6\end{array}$ & & $\begin{array}{r}.034- \\
.128\end{array}$ & & $\begin{array}{l}.101- \\
.467\end{array}$ & $\begin{array}{l}.003- \\
.030\end{array}$ & & $\begin{array}{l}0.59- \\
2.09\end{array}$ \\
\hline & $x$ & 19.7 & & .081 & & .257 & .012 & & 1.02 \\
\hline & SD & 2.62 & & .019 & & .071 & .005 & & 0268 \\
\hline
\end{tabular}




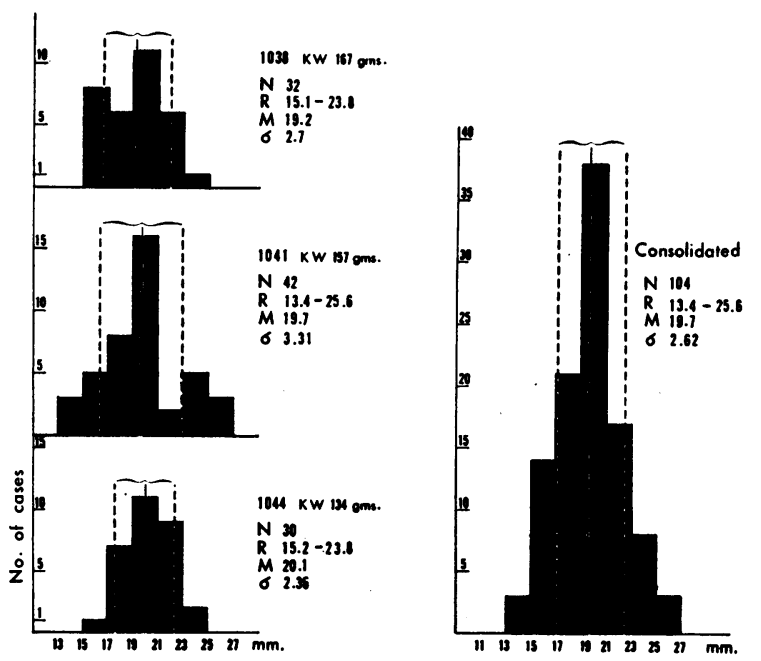

Fig. 1. Length of proximal convolutions in MAN.

0.155 and $0.300 \mathrm{~mm}$. Our more statistically valid 104 measurements agree closely with those of Pai in the case of proximal length and lie between those of the two investigators for glomerular diameter.

A consideration of the histograms in Figures 1-4 shows a striking difference between the statistical characteristics of the length of the proximal convolution and those of all other dimensions. The length is the most constant, both within and between individuals; mean and range in length are similar in all three cases, and the dispersion of variation is that of a sharply peaked normal frequency distribution. All other dimensions show greater statistical variability. In the case of the volume of the proximal convolution the means vary in magnitude in the three individuals as do the ranges, yet distribution in each and in the consolidated data still follows a normal, if flatter, curve.

Glomerular dimensions show greater variability. In the case of both surface and volume, the means of the individual cases are widely separated and the ranges in all are extended; moreover, there is a definite skew in the curve of frequency distribution of glomerular volumes in the consolidated data.

If, in general, structural variability is considered the expression of adaptation to environmental, i.e., functional, change, then the implication of these findings is that the varying activity known to exist in individual kidneys (4) is reflected by some other structural dimension than the relatively fixed length of the proximal convolution and that the structural correlates for functional variation probably lie among the three other more labile dimensions.

\section{The selection of structural correlates with func- tional activity}

Four dimensions are available from which expressions can be derived for correlation with the measurements of functional activity: the surface and volume of the glomerulus which puts glucose into the nephron by simple filtration, energy being supplied by the heart, and the length and volume of the proximal convolution which removes it by

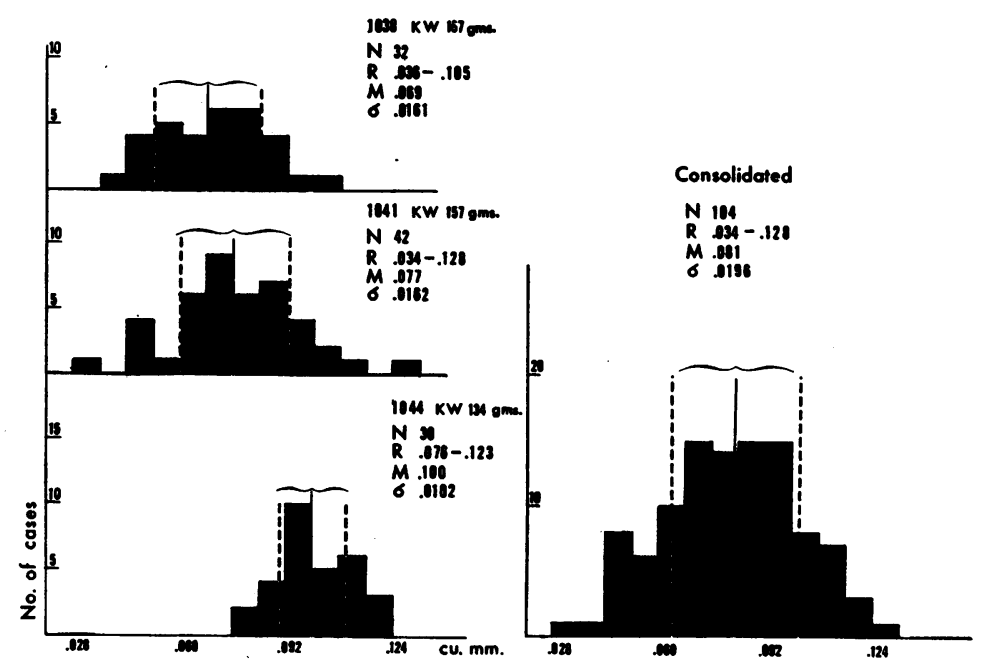

Fig. 2. Volume of proximat. convolutions in man. 


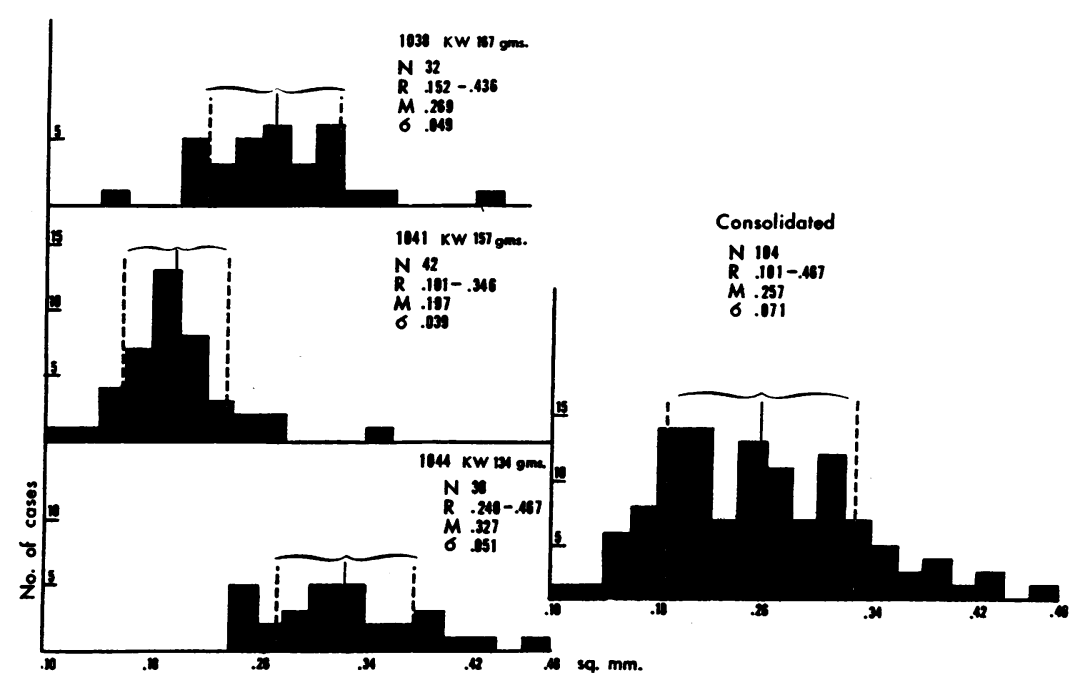

Fig. 3. Surface of glomerular tufts in man.

a mechanism of active transport energized by enzymatic action. It is at once clear that the simplicity of these structural dimensions cannot directly represent the complex detail of the functional processes; moreover, the measurements as made contain certain oversimplifications that are the result of technical limitations. We proceed, therefore, with no assumptions regarding the significance of the absolute values of the structural measurements but on the hypothesis that they will reflect some over-all constant relation to the functional data-a conclusion the validity of which can be judged by the results of the final correlation.

In considering the case of the glomerular filter, surface of the tuft might seem to be the appropriate correlate. This measurement can at best be only approximate, for the tuft is often neither a perfect sphere nor an ovoid that can be measured by simple diameters; moreover, the measurement as made includes the capsule, and a few microns are thus added to each dimension. More serious in its disturbing effect is the fact that the tuft is commonly divided into two or more lobes which add to its surface a quantity impracticable to measure.

On the other hand, since filtration might be determined at the capillary wall or at some internal membrane whose involutions closely fol-
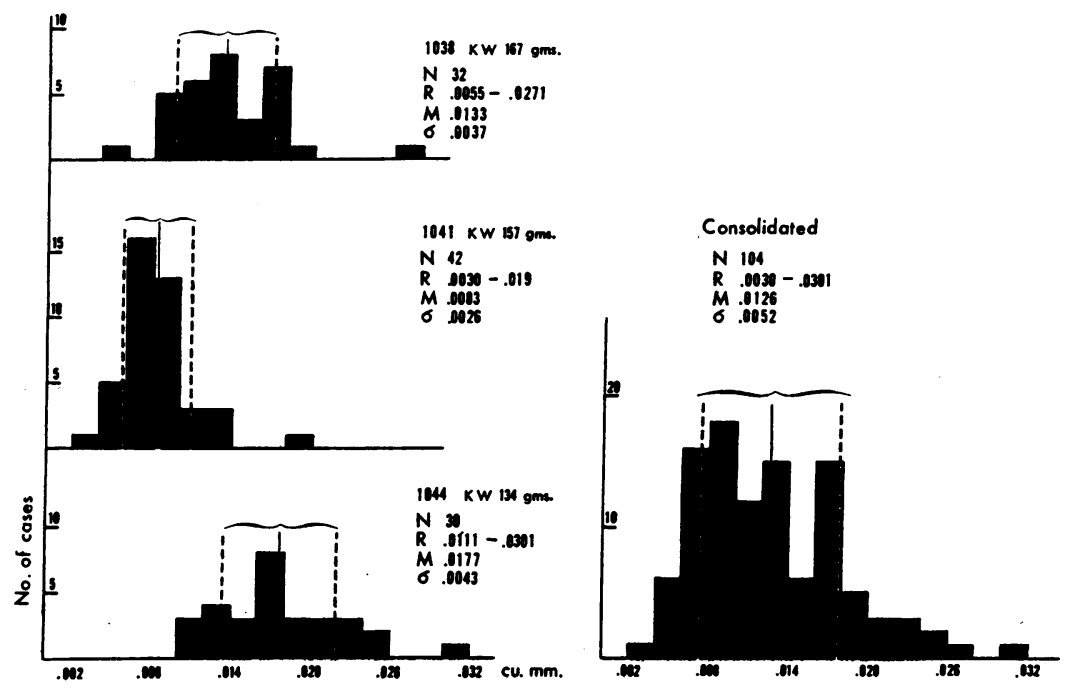

Fig. 4. Volume of glomerular tUfTS IN MAN. 
low the vascular ramifications, which are themselves directly immeasurable, it has been held that the filtration factor can be represented best by the volume of the channels that constitute the tuft $^{3}$ (18).

In the case of the reabsorbing convolution, it has generally been assumed in theoretical discussions that its length determines its efficacy $(9,18)$, a conclusion evidently based on the assumption that it is composed of equivalent cells which act ad seriatim on the glucose-containing fluid as it passes down the tubule. But the functional capacity of the convolution, as it is presented in the titration curve, is expressed as the degree of saturation of the reabsorptive mechanism of the tubular cells and this might well seem to be better represented by the cellular volume of the convolution. As stated previously (p. 1095), since there is no tubular lumen in the dissected specimens, the volume of convolution as measured corresponds closely to the volume of its epithelial cells. ${ }^{4}$

These uncertainties inherent in a speculative approach to the choice of the two structural correlates, glomerular and tubular, can be avoided by reliance upon the empirical proposition that informs the basic assumption of the proposed cor-

${ }^{3}$ For an appreciation of the technical difficulties involved and the conjectural assumptions required in attempts to measure accurately the "filtering surface" of the glomerulus, the reader is referred to Vimtrup (16) and Book (17). The two investigators arrive at figures which differ by 100 per cent: respectively, 0.78 and $0.3813 \mathrm{sq} \mathrm{mm}$.

${ }^{4}$ It has been suggested that the surface of the lumen of the proximal convolution should be considered as a correlate with the reabsorptive process and, since this datum was not available in the experimental material, that it could be hypothetically deduced from the external surface of the convolution in much the same manner as the surface of the glomerulus was taken to represent internal filtration barriers. This suggestion overlooks the fact that the lumen of the nephron, unlike that of rubber tubing, is not constant and can be seen in living as well as in fixed tissues to vary from 0 to a limit approaching the external diameter of the tubule. No such variation occurs between glomerular surface and the unknown internal barriers to filtration, for the tissues of the glomerular tuft, although distensible, are relatively

fixed under physiological conditions. In any case, since the surface of a cylinder of given size bears a direct relation to its volume, the former may be considered included in the latter. relation-namely, that the structural and functional aspects of a biological activity are, as is evident in processes of adaptation involving development and growth, so intimately related as to be expressions of an essential unity. ${ }^{1}$ If one pair of the four possible structural dimensions concerned in the filtration and reabsorption of glucose shows a close statistical relationship, this agreement can be assumed to have biological significance as indicating that it is the appropriate correlate for the corresponding pair of functional measurements.

One further preliminary comment is necessary: since the functional examination describes the distribution of activity among the nephrons constituting the kidney, the statistical manipulations of the structural measurements that are to be used in correlation must also keep the nephrons

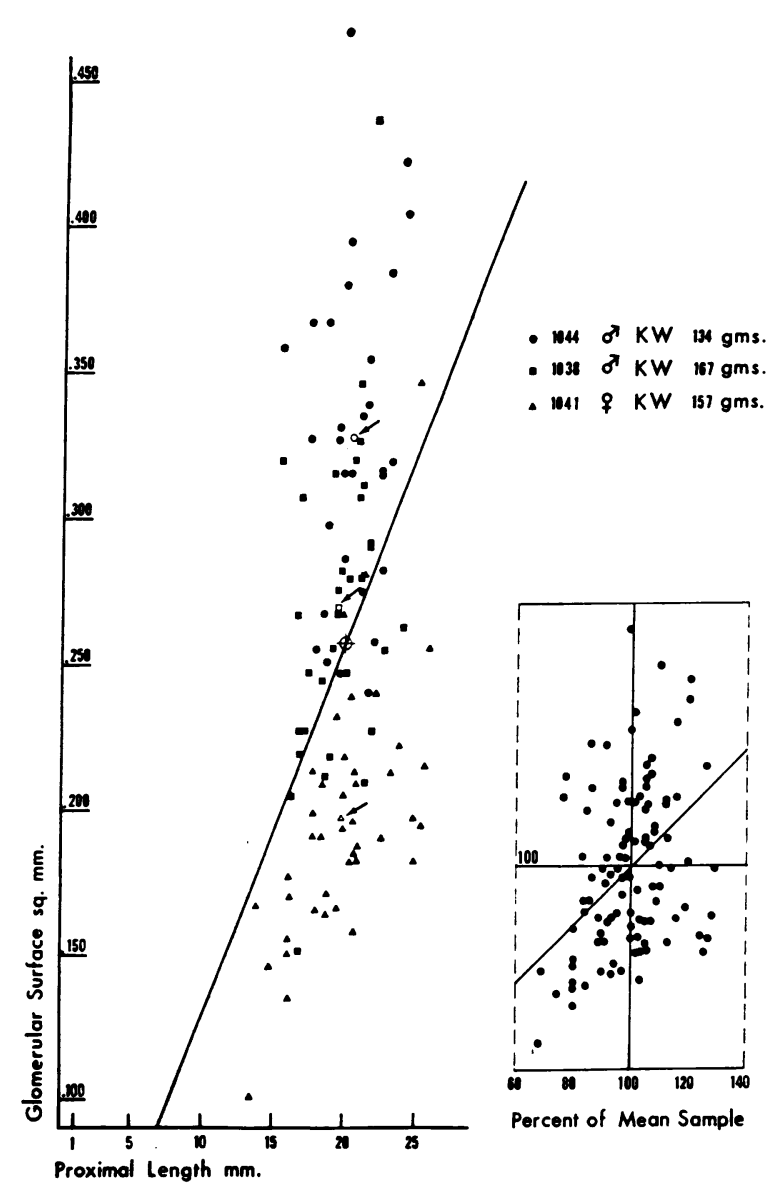

Fig. 5. Relationship of length of PROXimal CONVOLUTION TO GLOMERULAR SURFACE IN INDIVIDUAL NEPHRONS. 
intact ; that is, the measurements of each glomerulus must be related to those of its own particular convolution. The functional concept of glomerulotubular balance is thereby expressed in its structural aspect, and constitutes the first of the structural-functional equivalents (r) which we shall propose.

4. The structural expression of glomerulotubular - balance $(r)$ in the nephron

a. Proximal convolution length-glomerular surface. In Figure 5 the surface of the glomerular tuft ( $\mathrm{sq} \mathrm{mm}$ ) is plotted as ordinate against the length of the proximal convolution $(\mathrm{mm})$ as abscissa in each of the 104 individual nephrons of the three kidneys; the large open symbol indicates the mean values of both these measurements for the consolidated data and through it a straight line is drawn to the zero point. The small open symbols $(O)$ indicate the mean values in each of the three kidneys. In the insert the same dimensions for each nephron are plotted as percentage values of the calculated "average nephron" of the consolidated group.

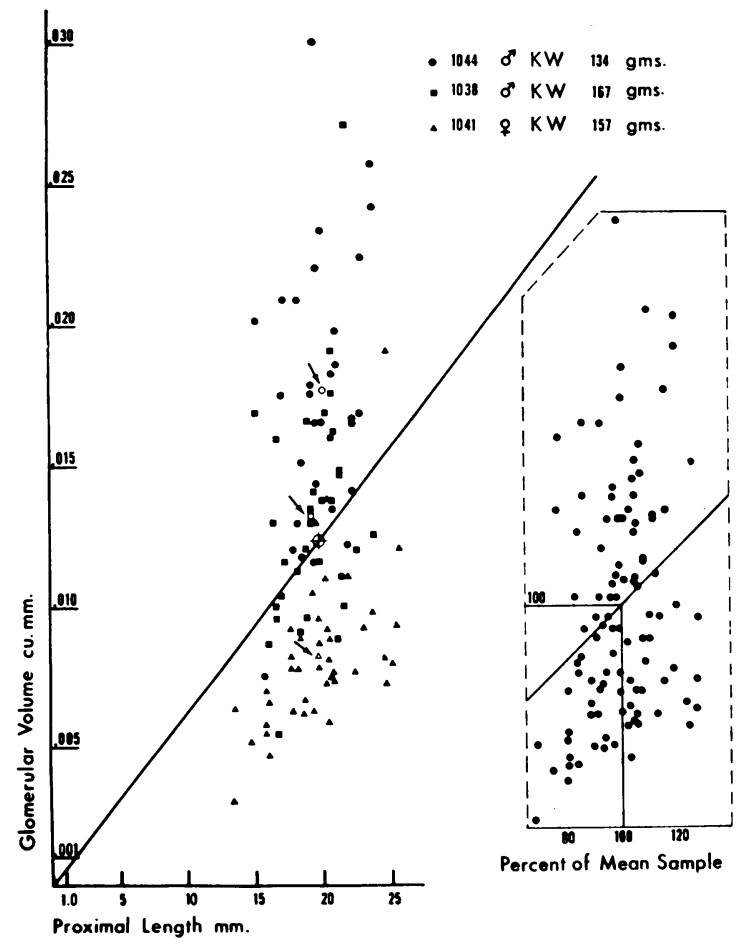

Fig. 6. Relationship of Length of the proximal CONVOLUTION TO GLOMERULAR VOLUME IN INDIVIDUAL NEPHRONS.

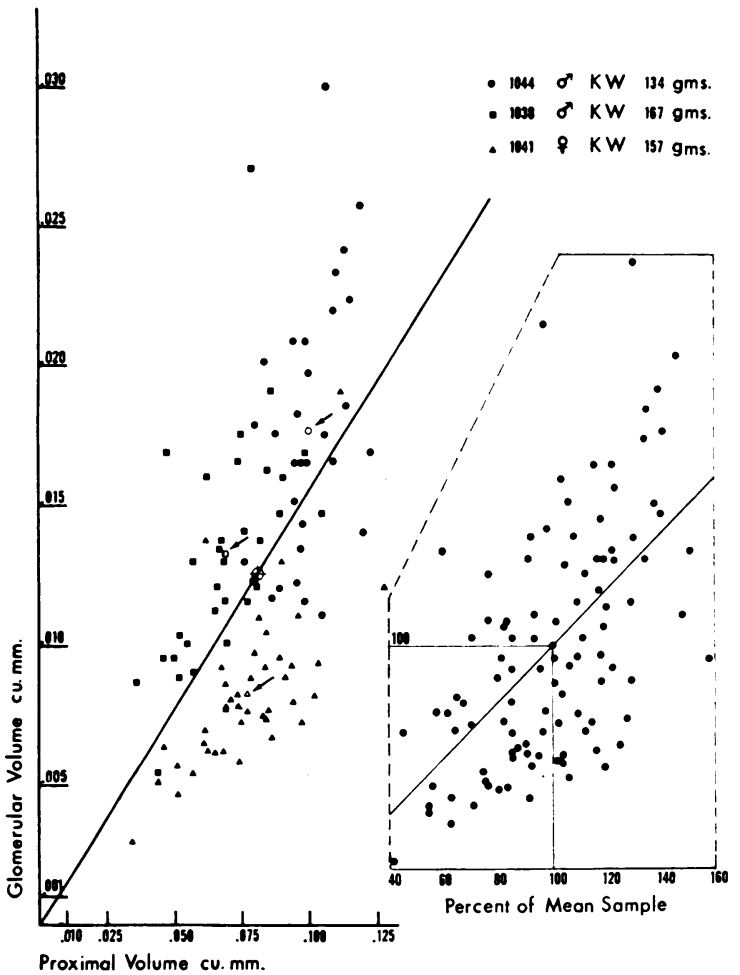

Fig. 7. Relationship of volume of the proximal CONVOLUTION TO GLOMERULAR VOLUME IN INDIVIDUAL NEPHRONS.

It will be noted that neither the ratios for the individual nephrons of the whole group nor the mean values of the ratios from the three kidneys $(\uparrow)$ follow the line of direct relation; in Table V, proximal convolutions of the same length (19.2 $\mathrm{mm}$ ) have glomeruli whose surfaces range from $0 . \dot{2} 32$ to $0.327 \mathrm{sq} \mathrm{mm}$. This lack of correlation between the two dimensions is also evident when the values of the ratios in the individual nephrons are expressed as percentages of the value of the "average nephron" of the consolidated group.

b. Proximal convolution length-glomerular volume. In Figure 6 the lack of relationship between these dimensions is even more evident than when glomerular surface was used as a correlate.

c. Proximal convolution volume-glomerular volume. Figure 7 reveals a definite tendency for the ratio of these two dimensions to follow the straight line of constancy; this is true both of individual nephrons from the three kidneys and the mean ratios from each of the kidneys.

d. Proximal convolution volume-glomerular surface. An even closer balance is observed in Fig- 
ure 8; judged from its statistical aspect, this is the most promising ratio of the two structural dimensions for correlation with the functional measurements.

\section{Structural-functional equivalents for the deter- mination of glomerular activity}

The theoretical description given by Smith (9) of the titration of glucose is based on the experimentally determined observations of Shannon and Fisher (3) and Shannon, Farber and Troast (19) on the kidney; and of Walker and Bott; Oliver and MacDowell (2) on the nephron.

The former have shown in the dog that, as the plasma level of glucose is progressively elevated, a point is reached where tubular reabsorption attains a constant maximal rate. Below the level of plasma glucose required to effect this tubular saturation, reabsorption of sugar is complete; above this level, such glucose as is filtered in excess of

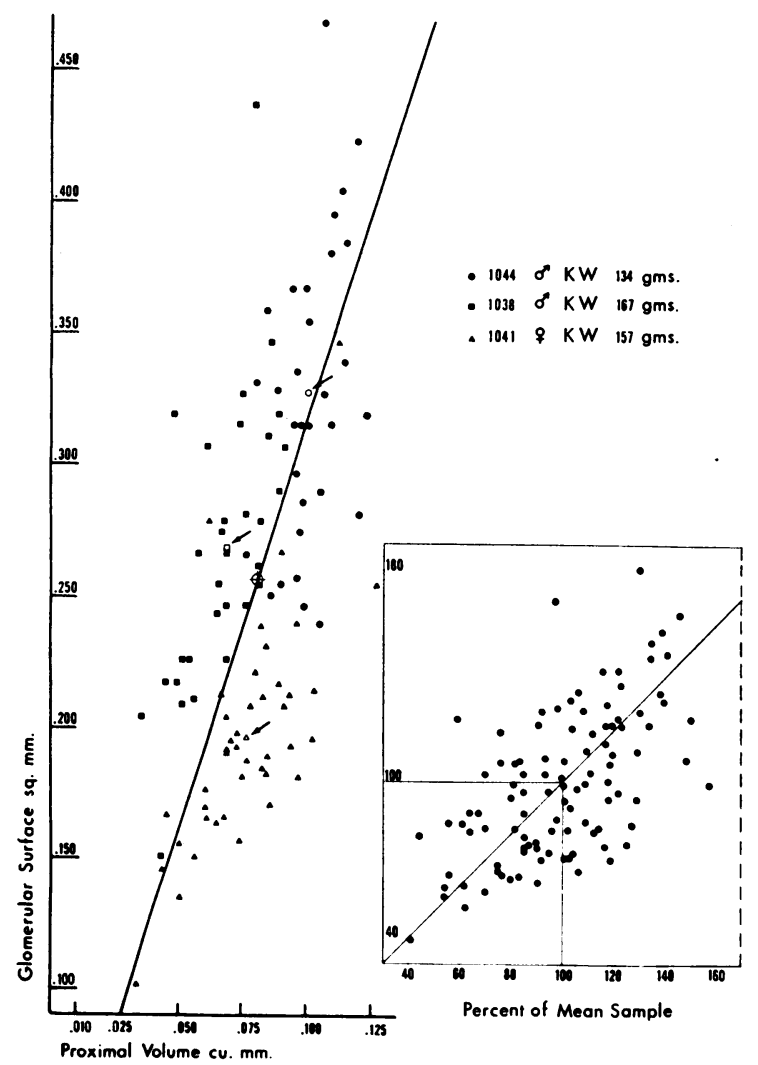

Fig. 8. Relationship OF VOLUME OF THE PROXIMAL CONVOLUTION TO GLOMERULAR SURFACE IN INDIVIDUAL NEPHRONS. the maximal rate of reabsorption is excreted in the urine.

The following summary of the theoretical analysis of Smith $(9 ;$ p. 87-97, 104-109) which forms the basis of the titration is necessary to determine what structural-functional equivalents will be used in our correlation and how they can be derived.

The quantity of glucose filtered per minute constitutes the load offered to the tubules for reabsorption; for the entire kidney this load (mg per $\min$ ) is the concentration of glucose in the glomerular filtrate, or $\mathrm{P}_{\mathrm{G}}(\mathrm{mg}$ per $\mathrm{cc})$ multiplied by the rate of filtration, $\mathrm{C}_{\mathrm{In}}$ (cc per $\min$ ); i.e., glucose load $=\mathrm{P}_{\mathrm{G}} \mathrm{C}_{\mathrm{In}}$. The rate of tubular reabsorption of glucose $T_{G}(\mathrm{mg}$ per $\mathrm{min})$ is the difference between this load and the quantity of glucose excreted in the urine: $T_{G}=P_{G} C_{I n}-U_{G} V$, where $U_{G}$ ( $m g$ per $\mathrm{cu} \mathrm{mm}$ ) is the urine glucose concentration and $\mathrm{V}$ ( $\mathrm{cu} \mathrm{mm}$ per min) is the urine flow. As $P_{G}$ is increased, $T_{G}$ remains equal to $\mathrm{P}_{\mathrm{G}} \mathrm{C}_{\mathrm{In}}, \mathrm{U}_{\mathrm{G}} \mathrm{V}$ being zero, until maximal reabsorptive capacity is reached; this maximal rate of tubular reabsorption is designated as $\mathrm{Tm}_{\mathrm{G}}$. The observation that $\mathrm{Tm}_{\mathrm{G}}$ is not significantly altered by injection of pyrogens which increase renal blood flow or by caffeine, which increases the total filtration rate, is considered strong evidence against the occurrence of intermittency of glomerular filtration, a possibility suggested by certain observations on the amphibian kidney and which, if true for mammals, would complicate the titration theory.

The development of these general propositions from the level of the abstract kidney to the level of the actual nephrons is made possible by the direct observations of Walker and co-workers (2). For individual nephrons, or functionally homogeneous categories of nephrons, filtration rate is indicated by $c_{i n}$, the rate of glucose reabsorption by $t$ and the maximal reabsorptive capacity by $t m$. Since a common stream of plasma supplies all nephrons, $\mathrm{p}_{\mathbf{g}}$ will be equal to $\mathrm{P}_{\mathbf{G}}$, while $\mathrm{c}_{\mathrm{in}}$ will differ in various nephrons in consequence of differences in size of the glomerulus and glomerular pressure, while tm will differ "if for no other reason, because the proximal convolution does not in all nephrons have the same size and length" (9). In any particular nephron, the critical concentration of glucose required to effect saturation of its proximal convolution will vary directly as 
the maximal reabsorptive capacity of the tubule and inversely as the rate of filtration at the glomerulus; i.e., nephrons with the largest $c_{i n} / t m$ ratio will saturate at the lowest $\mathrm{P}_{G}$, while those with the lowest $c_{\text {in }} / \mathrm{tm}$ ratio will require a higher $P_{G}$.

The ratio $\mathrm{c}_{\text {in }} / \mathrm{tm}$ is designated as $\mathrm{r}$, "glomerular activity." Nephrons which have the same $c_{\text {in }} / \mathrm{tm}$ ratio are designated as a "category" in respect to "glomerular activity"; they may have different absolute values of $c_{i n}$ and $t m$ but these cannot be determined by the functional procedure. As opposed to $r$, which concerns individual or categories of nephrons, $\mathrm{R}$ is postulated to represent "total glomerular activity" of the entire kidneys; i.e., $\mathrm{C}_{\mathrm{In}} / \mathrm{Tm}_{\mathrm{G}}$, and this is shown to be equal to the mean value of $c_{i n} / t m$.

A development of the equations, based on a successive saturation of the nephrons as the load upon them is increased, leads to the final conclusion that, since $\Sigma c_{i n} / t m$ is identical with $C_{I n} /$ $\mathrm{Tm}_{\mathrm{G}}$, and the maximal reabsorptive capacity of any category is equal to the load at which saturation first occurs $\left(\mathrm{C}_{\mathrm{In}} \mathrm{Pg}=\mathrm{tm}_{\mathrm{g}}\right)$ for that category, then:

$$
\mathrm{r} / \mathrm{R}=\frac{\mathrm{c}_{\mathrm{in}} / \mathrm{tm}}{\mathrm{C}_{\mathrm{In}} / \mathrm{Tm}_{\mathrm{G}}}=\frac{1}{\mathrm{P}_{\mathrm{G}} \mathrm{C}_{\mathrm{In}} / \mathrm{Tm}_{\mathrm{G}}} .
$$

This ratio is called the "relative glomerular activity" of a particular category of nephrons. The last term of this equation can be solved by substitution of experimentally determined measurements.

Accepting these propositions as a theoretical description of the functional aspect of the handling of glucose by the nephrons and the kidney, it is possible to introduce structurally derived equivalents for certain factors in the equations. As previously mentioned, the selection of these equivalents from among the various possible structural dimensions is made on the basis of the high degree of statistical correlation that exists between certain of them; namely, the surface of the glomerulus and the volume of proximal convolution.

From the results of direct observation of the process in the nephron (2) we may conclude, under the same general assumptions as those used in the functional analysis and subject to the qualifications previously mentioned (p. 1101) in regard to certain simplifications in the procedures of measurement, that the rate of filtration of glucose in a concentration equal to that in the plasma will vary as the surface of the filter-i.e., the glomerular tuft ; $c_{\text {in }}$ is thereby equated, at least relatively, with the area of this surface (gs) expressed in square millimeters. Saturation of the reabsorptive component with glucose, $\mathrm{tm}_{\mathrm{g}}$, will vary as the volume of tubule to be saturated; i.e., $\mathrm{tm}_{\mathrm{g}}$ is equated with $\mathrm{pv}$, the volume of the proximal convolution expressed in cubic millimeters. $C_{I n}$, expressed structurally, becomes a function of $\Sigma$ gs, the sum of the surfaces of all the individual tufts of the kidney, a figure that can be calculated from the mean value of the measured nephrons and the known number of glomeruli per gram of kidney weight ; in contrast to most current statistical data concerning nephrons, this value has been firmly established by independent investigators $(16,20)$. In the same manner $\mathrm{Tm}_{\mathrm{G}}$ may be expressed as $\Sigma$ pv, the sum of all the proximal volumes. On these assumptions, the essential ratios of the functional description become in structural terms:

$$
\begin{aligned}
\mathrm{r} & =\frac{\text { glomerular surface }(\mathrm{sq} \mathrm{mm}) \text { of a particular nephron }}{\text { proximal volume }(\mathrm{cu} \mathrm{mm}) \text { of a particular nephron }} \text { or } \frac{\mathrm{gs}}{\mathrm{pv}} \\
\mathrm{R} & =\text { mean value of } \mathrm{r} \text { of all nephrons } \\
\mathrm{r} / \mathrm{R} & =\frac{\text { glom. surf./prox. vol. of a particular nephron }}{\text { mean value of (glom. surf./prox. vol.) of all nephrons }} \text { or } \frac{\mathrm{gs} / \mathrm{pv}}{\mathrm{MGS} / \mathrm{PV}}
\end{aligned}
$$

The values of $r$ have appeared previously as the points in Figure 8; their calculated values and those of $r / R$ are given in Tables II-V. A summary list of the proposed structural-functional equivalents appears in Table VI.
6. The distribution of relative activity $(r / R)$ among nephrons in the human kidney as indicated by functional and structural measurements

From 150 observations on 10 normal humans, Smith and colleagues $(4,9)$ have determined the 
TABLE VI

Proposed structural and functional equivalents

\begin{tabular}{|c|c|c|}
\hline Functional measurement & & Structural equivalent \\
\hline Rate of filtration in a particular nephron & $c_{\text {in }}$ & $\begin{array}{l}\text { Surface of glomerular tuft of a particular nephron } \\
\text { (sq mm) }\end{array}$ \\
\hline Glomerular filtration rate $(\mathrm{cc} / \mathrm{min})$ & $\mathrm{C}_{\mathrm{In}}$ & Sum of all glom. tuft surfaces \\
\hline $\begin{array}{l}\text { Rate of glucose reabsorption in a particular saturated } \\
\text { nephron }(\mathrm{mg} / \mathrm{min})\end{array}$ & $\mathrm{tm}$ & $\begin{array}{l}\text { Vol. of proximal convolution of a particular nephron } \\
\text { (cu mm) }\end{array}$ \\
\hline Max. value of total reabsorption in all nephrons & $\mathrm{Tm}$ & Sum of all prox. volumes \\
\hline $\begin{array}{l}\text { "Glomerular activity" }\left(c_{\mathrm{in}} / \mathrm{tm}\right) \text { in a particular } \\
\text { nephron }\end{array}$ & $\mathbf{r}$ & $\frac{\text { Glom. surf. (sq mm) }}{\text { Prox. vol. (cu mm) }}$ of a particular nephron \\
\hline $\begin{array}{l}\text { Total glomerular activity of both kidneys } \\
\mathrm{C}_{\mathrm{In}} / \mathrm{Tm}=\text { mean value } \mathrm{C}_{\mathrm{In}} / \mathrm{tm}\end{array}$ & $\mathrm{R}$ & Mean value of $r$ of all nephrons \\
\hline $\begin{array}{l}\text { Relative glomerular activity of a particular category } \\
\text { of nephrons } \\
\frac{c_{\text {in }} / \mathrm{tm}}{\mathrm{C}_{\mathrm{In}} / \mathrm{Tm}}=\frac{1}{\mathrm{Pg} \mathrm{C} \mathrm{Cn}_{\mathrm{n}} / \mathrm{Tm}}\end{array}$ & $\mathrm{r} / \mathrm{R}$ & $\frac{\text { Glom. surf./prox. vol. of a particular nephron }}{\text { Mean value glom. surf./prox. vol. all nephrons }}$ \\
\hline
\end{tabular}

distribution of glomerular activity among the nephrons of a hypothetical kidney by constructing a frequency distribution curve in which categories of nephrons are plotted with $\mathrm{r} / \mathrm{R}$ as abscissae and $\mathrm{tm} / \mathrm{Tm}$ as ordinates. The smoothed curve is considered by them to be practically identical with a symmetrical normal frequency distribution; they conclude that in the normal human kidney glo- merular activity in regard to the handling of glucose is distributed about the mean in such a dispersion that 95 per cent of the observations fall within \pm 40 per cent of the mean.

A similar statistical procedure was applied to the structural dimensions of 104 nephrons from the normal individuals, $r / R$ as the abscissae being represented by the structural-function equivalent:

$$
\frac{\text { glom. surf./prox. vol. of a particular nephron }}{\text { mean value (glom. surf./prox. vol.) of all nephrons }} \text { or } \frac{\mathrm{gs} / \mathrm{pv}}{\mathrm{MGS} / \mathrm{PV}} \text {, }
$$

and $\mathrm{tm} / \mathrm{Tm}$ as ordinates being represented by:

$$
\frac{\text { prox. vol. of a particular nephron } \times 100}{\text { sum of all prox. vols. }}=\frac{100 \mathrm{pv}}{\sum \mathrm{pv}} .
$$

The resulting frequency distribution is shown in Figure 9; superimposed upon it are the functional data of Smith and colleagues $(4,9)$ transformed for more exact comparison from a curve to a stippled histogram. The two coincide to such a degree that it can be concluded that the structural dimensions of the components handling glucose are distributed in the normal human kidney in the same manner as are their functional characteristics.

Comment. In the smoothed distribution curve originally presented by Smith and co-workers (4, 9) there is a distinct skew which is less evident in the rearrangement of their data in form of a histogram; this skew is present in the histogram derived from the structural data. The great sensitivity of the distribution, also remarked in their functional data by Smith and co-workers, is illustrated by the extension of the base of the structural histogram beyond 1.70 ; this was the result of 3 nephrons in the 104 cases.

\section{Observations on the distribution of functional activity among the individual nephrons}

In the theoretical description of the procedure of titration (9) the term individual nephron is parenthetically qualified: (or a functionally homogeneous category of nephrons); it is further stated that a category having a certain $\mathrm{c}_{\text {in }} / \mathrm{tm}$ ratio (r) may include individual nephrons with different absolute values of $c_{\text {in }}$ or tm but that these are data which cannot be determined by the functional procedure.

The structural measurements, however, are 

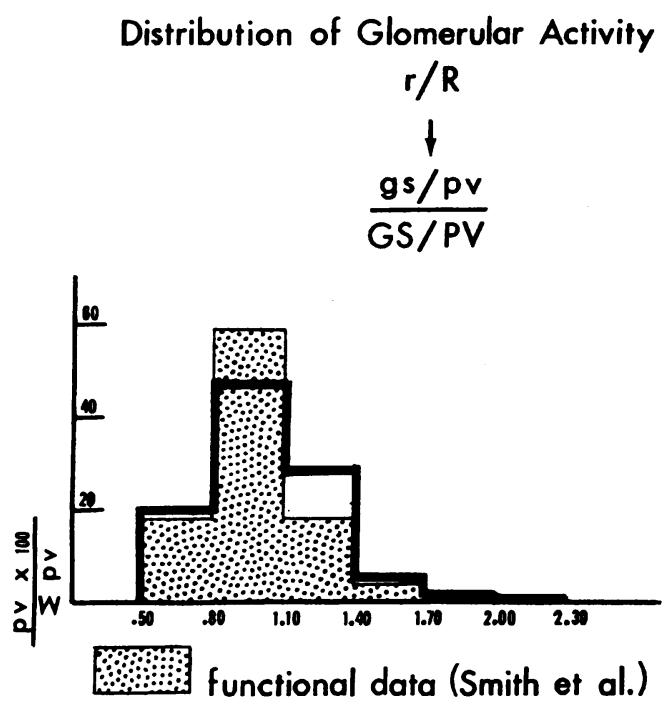

Fig. 9. Comparison of the distribution of RElative GLOMERULAR ACTIVITY AS DERIVED FROM FUNCTIONAL AND STRUCTURAL MEASUREMENTS.

made on isolated nephrons which preserve intact the glomerulus and its attached convolution, and this makes possible more detailed examination of the distribution of activity among them insofar as it is represented by structural-functional equivalents.

Reference to Figure 8, in which the structural equivalents of glomerular activity $(\mathrm{gs} / \mathrm{pv}=\mathrm{r})$ are plotted, or to Table $\mathrm{V}$, in which numerical values appear, shows that in 104 nephrons $r$ was identical with the third place in five pairs whose absolute glomerular and tubular dimensions vary widely (nephrons 1-70, 55-97, 28-104, 9-18 and 79-86). The coincidence of relative glomerular activity $(r / R)$ is equally frequent as can be seen by following the ordinates of Figure 10 or in the figures of Table $\mathrm{V}$ where as many as six nephrons have identical ratios $(10,25,62,78,84,95)$. Nephrons with a proximal volume of $0.112 \mathrm{cu} \mathrm{mm}$ (no. 4) and $0.051 \mathrm{cu} \mathrm{mm}$ (no. 98) have the same value of $r / R(0.97)$ or nephrons with the identical proximal volume of $0.09128 \mathrm{cu} \mathrm{mm}$ (nos. 34, 39) have $r / R$ ratios of 0.72 and 1.07 .

Histogram A of Figure 10, constructed from the data of individual nephrons in the three kidneys, is similar to Figure 9 which is derived from categories of nephrons, but it demonstrates the actual scatter of the ratios of the individual nephrons from the three kidneys. The cause of the skew which is so evident in the distribution of ratios based on both functional and structural measurements in the two superimposed histograms of Figure 9 now becomes apparent.

In Figure 10 the total population of 104 nephrons is approximately equally divided in regard to the volume of their proximal convolutions above and below the average value $(0.081 \mathrm{cu} \mathrm{mm})$. In 53 nephrons where proximal convolution volume is greater than the average, 34 are below the mean (1.02) in relative glomerular activity for nephrons irrespective of size, and 19 above, while in 51 nephrons whose proximal volumes are less than average, the distribution of $r / R$ is reversed28 lying above and 23 below the mean ratio. Proximal convolutions with greater than average volume have a mean $r / R$ of 0.93 , whereas those with less than average proximal volume have a mean ratio of 1.11 . Selected on the basis of their relative glomerular activity, three of the four highest ratios are found in nephrons with small proximal convolutions, and the three lowest ratios in nephrons with large proximals.

It is therefore apparent that the skew in the distribution of relative glomerular activity among

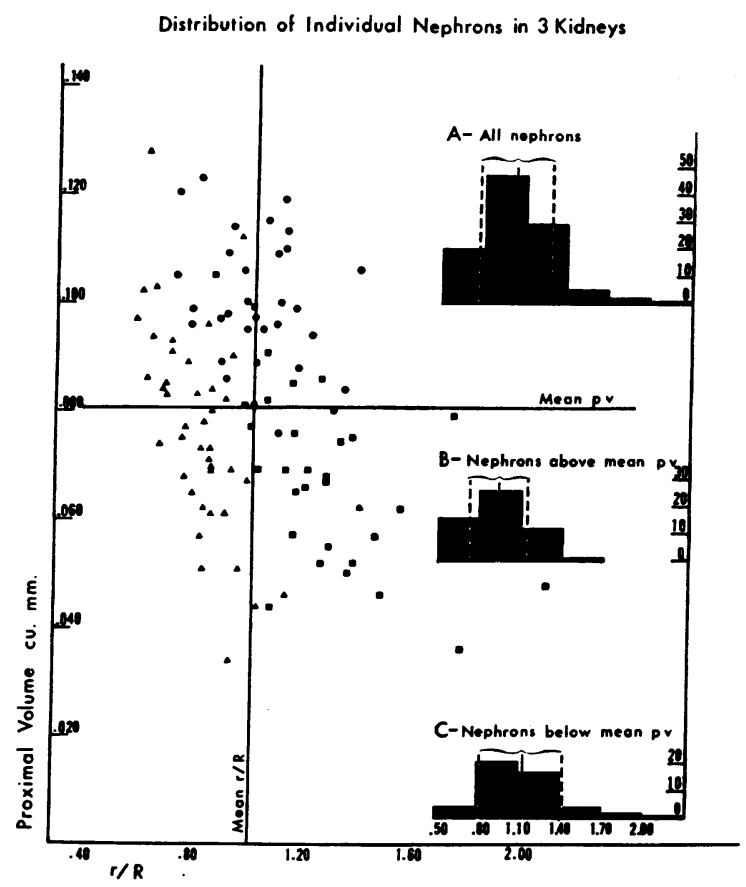

Fig. 10. Distribution of Relative glomerular aCTIVITY IN INDIVIDUAL NEPHRONS IN RELATION TO VOLUME OF PROXIMAL CONVOLUTION. 
the nephrons in the hypothetical kidney constituted on the basis of the consolidated structural data, is related to the "size" of the nephrons, those with large proximal convolutions having low ratios of relative glomerular activity and those with smaller proximal volumes having higher ratios. ${ }^{5}$ This is evident in the inserted histograms $B$ and $C$ of Figure 10, showing the distribution of $r / R$ of nephrons whose proximal volume lies above and below average size.

Accepting provisionally the validity of the structural-functional equivalents, these observations agree (i.e., correlate) with the conclusions which follow from the functional theory and extend and confirm the theory by an actual demonstration of the relationship of the individual nephrons to the kidney which their sum constitutes.

Comment. These conclusions may have significance in situations involving growth of the nephrons, that due either to normal increase with age or to "compensatory hypertrophy," since in both cases it has been shown that the proximal convolution grows in a distinctive manner (21). The implication of this earlier observation was that in adaptation to functional increase the proximal

5 A comparison of the structural data for specific individual nephrons as they appear in Tables II-V affords an interesting and, what is rare, a concrete example of one distinction between a hypothetical or ideal kidney and a real kidney. In both its functional (cf. p. 1106) and structural aspects, the former is constituted of consolidated data from several individual kidneys; in the case of the structural presentation, of 104 nephrons from three kidneys. These nephrons had not developed, grown and functioned in a common association and environment, although conditions in all of the individuals from which they came were presumably similar-i.e., "normal." The relationships between nephrons are therefore somewhat different from those that obtain in the actual kidney of an individual (Subject 1041) as can be seen by comparing the structural data of the first, and largest, nephron in Table III with that shown for the same nephron in Table $\mathrm{V}$. The same dimensions appear in each and $r$, which concerns the particular nephron, is identical; but $r / R$, which represents the relationships of this nephron to its fellows as they existed during the life of the individual, is 0.77 in the real kidney, whereas it is 0.63 in the hypothetical organ. In the case of the smallest nephron, the last item in Tables III and V, the difference between $r / R$ is 0.94 and 1.16. The reason for these differences is that relative glomerular activity-i.e., the relationship of glomerulotubular balance in the individual nephron to that of the kidney-differs in the two cases, being 3.22 in the hypothetical or ideal kidney and 2.62 in the real. convolution responds by relatively greater growth than do other tubular segments of the nephron; the present findings indicate that it also grows relatively more than its glomerulus, with a corresponding shift in glomerulotubular balance. Smith notes $(18$, p. 513$)$ that in children who have growing proximal convolutions, glucose reabsorptive capacity is much more highly developed relative to glomerular function than in adults, and Kolberg (22) has recently examined the same problem in compensatory hypertrophy after nephrectomy. Until definitive quantitative structural data in these situations are available, the problem remains in the field of speculation.

\section{The structural homogeneity of the renal cortex}

Another question concerning individual nephrons is the possible variation in their size depending upon their point of origin in the cortex. Since there may be a difference of a centimeter in the distance traversed by proximal convolutions arising from glomeruli near the surface of the kidney and those lying near the corticomedullary junction, and since all end at the same level in the medulla, it might be assumed that there would be considerable resulting differences in length. Glomeruli lying near the corticomedullary junction have also been described as larger (23). Although there is no direct evidence by micropuncture, since to the present time only the outermost glomeruli have been accessible to the pipette, various speculative functional significances have been assigned to these equally hypothetical structural variations.

In Figure 11 the dimensions of glomeruli and proximal convolutions in the outermost, middle and lowest third of the cortex are shown; they may be compared with the undistributed consolidated data of Figures 1,2 and 3. In summary, it may be stated that from the structural standpoint a rather remarkable cortical homogeneity is observed; the outermost nephrons have only a moderately greater length (mean $=21.5$ ) as compared with the lowermost $(M=17.7)$ and the same is true of their volumes $(\mathrm{M}=0.088 ; \mathrm{M}=0.075)$, although it is a fact that somewhat larger proximals are derived from outermost glomeruli. Glomerular surfaces show even less variation in the three zones; their variability is greatest, however, in the lower zone. The distribution of ratios of 


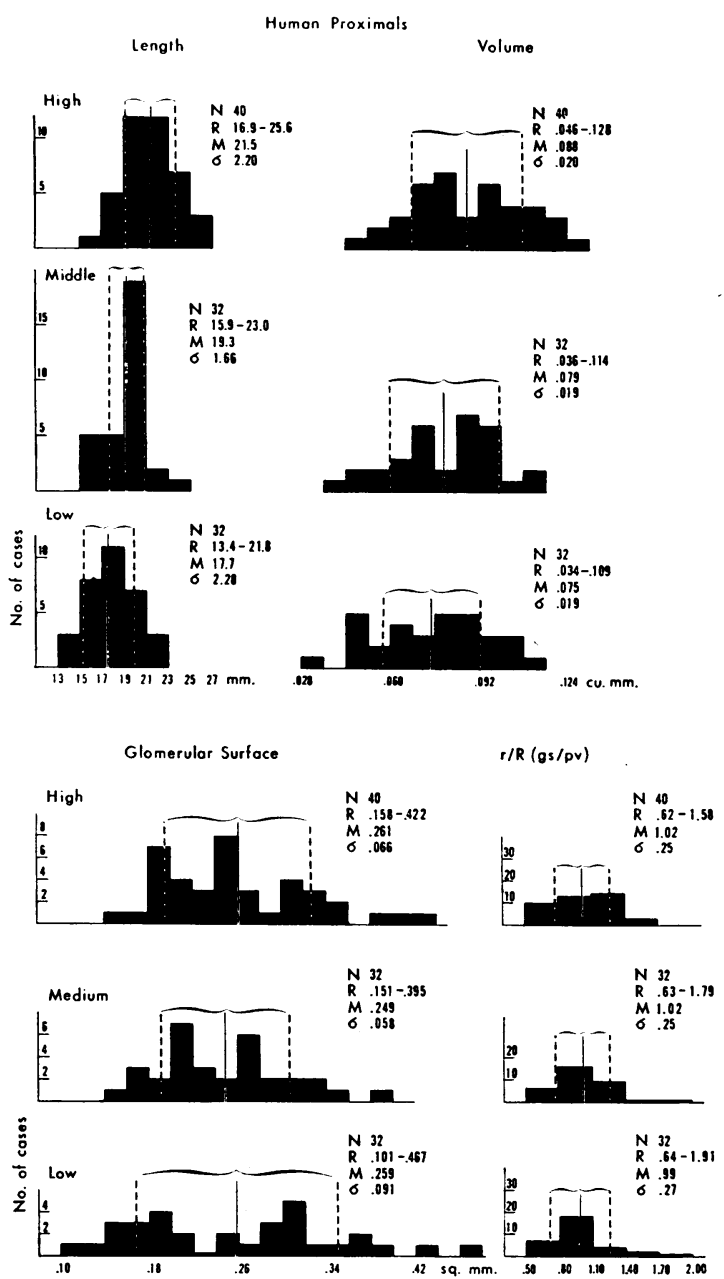

Fig. 11. Dimensions of proximal convolutions AND GLOMERULI IN OUTER, MIDDLE AND LOWER ZONES OF THE CORTEX.

relative glomerular activity of the nephrons is essentially similar in the three zones (Figure 11). There is, therefore, no structural evidence that nephrons from different levels of the cortex should behave very differently in the handling of glucose.

\section{THE STRUCTURAL-FUNCTIONAL EQUIVALENTS APPLIED IN CORRELATION WITH FUNCTIONAL} MEASUREMENTS

In his discussion of the "glucose threshold" Smith $(24$, p. 38) points out that, although the existence of a maximal reabsorptive rate for glucose is in principle responsible for this phenomenon, since both $\mathrm{Tm}_{\mathrm{G}}$ and GFR vary in different subjects it cannot be identified, as was the original implication, with any fixed plasma concentration.
As micropuncture and dissection show (2), a structural factor imposes a similar qualification on this concept-namely that, although in principle the threshold is determined by the fact that under normal circumstances approximately onehalf of the proximal convolution is "in reserve" for the reabsorption of an increase in filtered load, as the present measurements have indicated, the amount of this reserve varies in different nephrons and in individual kidneys. ${ }^{6}$

Smith therefore considers it more pertinent, in comparing the functional characteristics of the kidneys of individuals, to consider the ratio GFR/ $\mathrm{Tm}_{\mathrm{G}}$; i.e., $\mathrm{C}_{\mathrm{In}} / \mathrm{Tm}_{\mathrm{G}}$, rather than a "threshold," and this ratio in normal men averages $0.37 \pm$ 0.05 and in normal women $0.39 \pm 0.06$.

The structural data for the calculation of this ratio from the structural-functional equivalents are shown in Table VII.

The crucial correlation in the form of a "composite" titration curve can now be constructed by using a combination of the functional and structural measurements; this can be accomplished by computing from the structural data the loads at which saturation would occur in each group of nephrons having the same ratio of glomerular surface-proximal volume, beginning with the lowest load and calculating the corresponding figure for reabsorption from the sum of the proximal volumes theoretically contributing at each successively higher value. A complete theoretical development of these transformations from structural to functional form will be found in the following report (25) where both sorts of measurements are derived from the same kidney of the dog. The result of such computation is shown in the composite titration curve (Figure 12) in which the points of saturation were calculated from the anatomical data, and the dotted line of the splay is the smoothed curve derived by Smith and colleagues (Figure 6 in Reference 9) from their functional data.

6 This "reserve" of proximal convolution is responsible for the apparent anomaly encountered in histological examinations of the kidneys in acute tubular necrosis where extensive proximal damage may be present with no glycosuria although $\operatorname{Tm}_{\mathrm{G}}$ is reduced. When the proximal convolutions in such cases are examined in their continuity by microdissection, it is found that a great part and often the first half of the proximal convolution has escaped damage (12, p. 1362). 
TABLE VII

Structural data from dissected kidneys

\begin{tabular}{|c|c|c|c|c|c|c|c|}
\hline & & $\underset{\text { wt }}{\text { Kidney }}$ & $\begin{array}{c}\text { No. of } \\
\text { nephrons* }\end{array}$ & MPV & $\Sigma$ pvt & MGS & $\Sigma$ gs $\ddagger$ \\
\hline & & $g$ & & \multicolumn{2}{|c|}{$c u m m$} & \multicolumn{2}{|c|}{$s q m m$} \\
\hline 1038 & $\sigma^{7}$ & 335 & $2,345,000$ & 0.069 & 161,805 & 0.269 & 630,805 \\
\hline 1041 & q & 314 & $2,198,000$ & 0.077 & 169,246 & 0.197 & 433,006 \\
\hline 1044 & $\sigma^{+}$ & 268 & $1,876,000$ & 0.100 & 187,600 & 0.327 & 613,452 \\
\hline
\end{tabular}

* Kidney weight $\times 7,000$. Average value from Vimtrup (16) and Kittelson (20).

$\dagger \Sigma$ pv $=$ sum of all proximal volumes.

$\ddagger \Sigma$ gs $=$ sum of surfaces of all individual tufts.

Assuming $\mathrm{Tm}_{\mathrm{G}} / \sum \mathrm{pv}=\mathrm{k}$, then $\mathrm{Tm}_{\mathrm{G}}=\mathrm{k} \sum \mathrm{pv}$ :

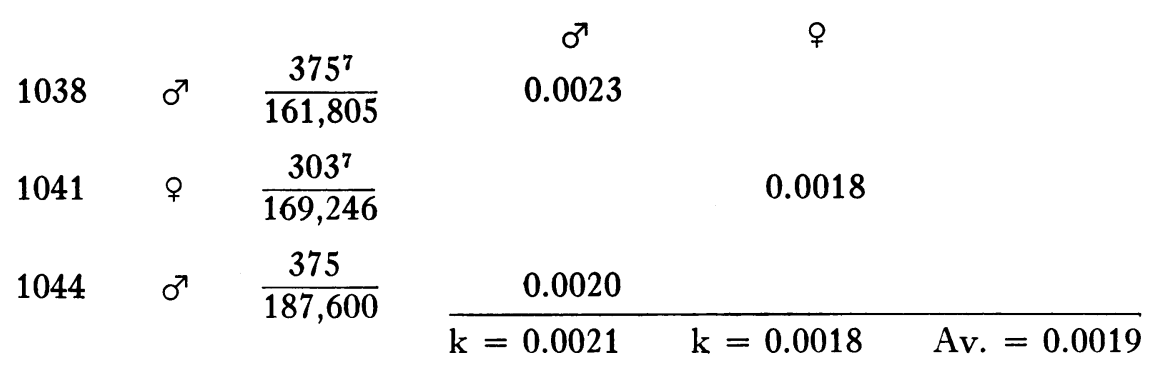

And if GFR $/ \sum$ gs $=k$, then GFR $=k \sum$ gs:

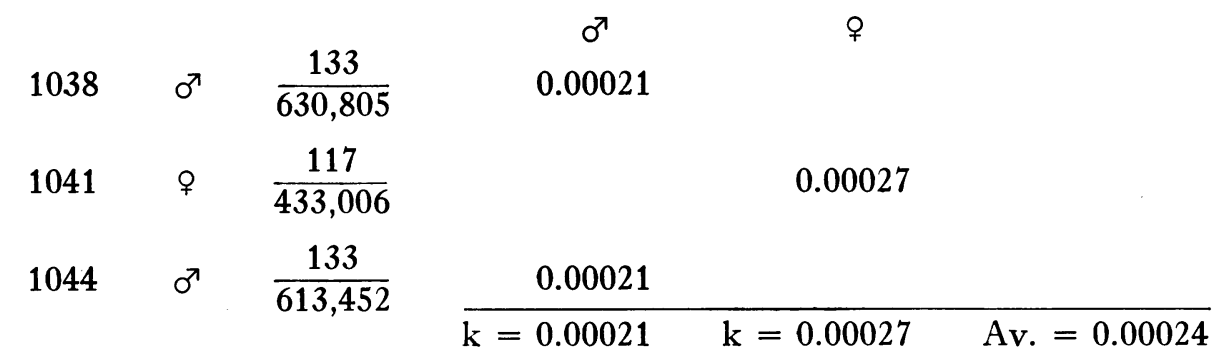

On these assumptions, the ratio becomes:

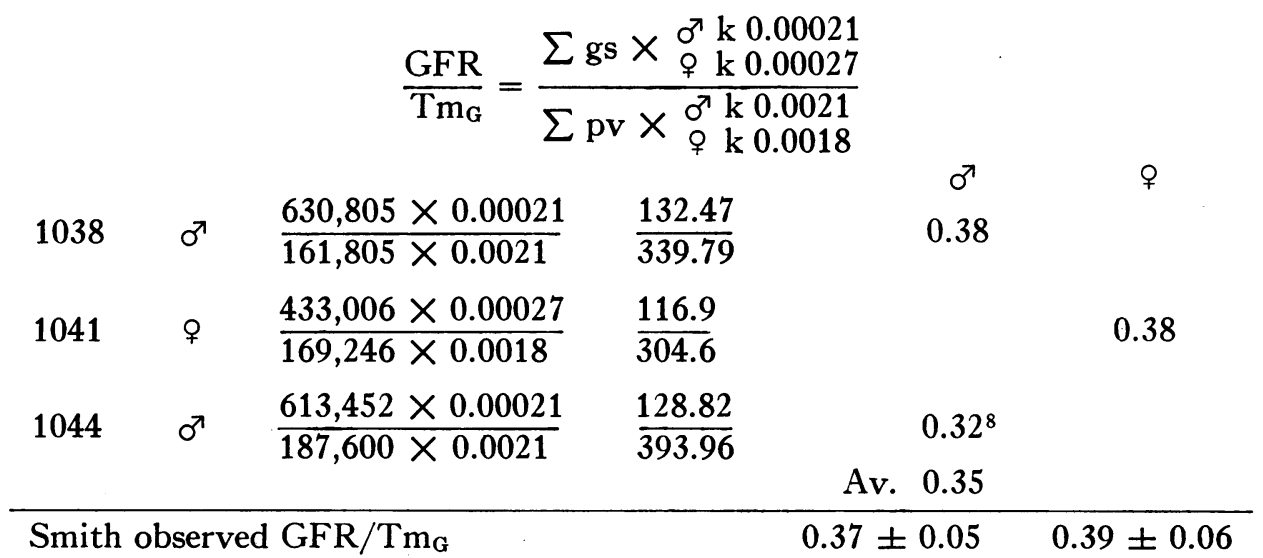

7 Mean values for normal men and women from Smith (9, pp. 96-97).

8 A small kidney with a large proximal volume relative to its more "normal" glomerular surface; similar to Smith's case, T.T., $166 / 536=0.31$ (9, p. 96). 


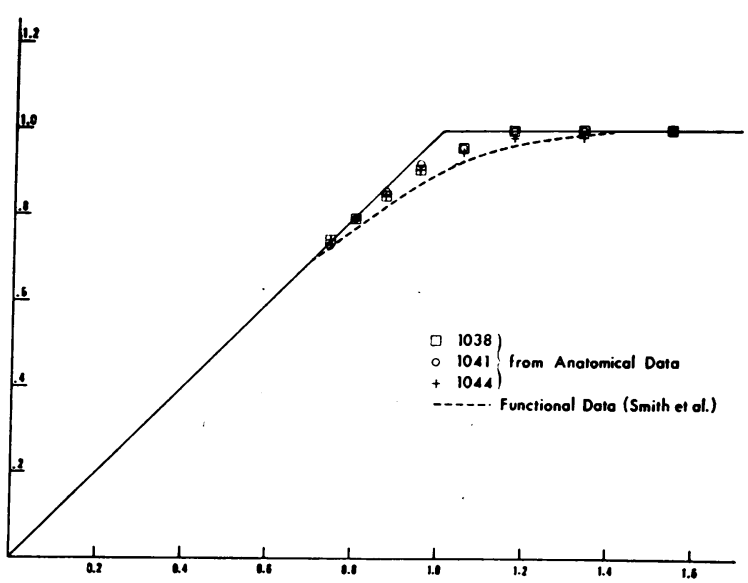

Fig. 12. Composite glucose titration curves calcuLATED FROM ANATOMICAL AND FUNCTIONAL MEASUREMENTS.

\section{DISCUSSION ${ }^{1}$}

It has proved possible to substitute in the theoretical functional description of the handling of glucose by the nephrons of the human kidney (4, 9) structural measurements of the components known to be solely responsible (2) for its filtration and reabsorption. By the use of certain equivalents the functional description of the frequency distribution of "relative glomerular activity" ( $r / R$ ), as well as GFR and $\mathrm{Tm}_{\mathrm{G}}$ and their ratio $\left(\mathrm{GFR} / \mathrm{Tm}_{\mathrm{G}}\right)$ has been reproduced from the structural measurements, and the "titration curve" of tubular saturation with its typical splay has been constructed by using anatomical and functional measurements as equivalent data.

In short, this particular renal activity can be quantitatively described in identical terms in two ways: either by using the anatomical dimensions of the operating components (glomeruli and proximal convolutions) or by the measurement of the dynamic movements of glucose between blood and urine that occur during its filtration and reabsorption.

Since the terms of the functional description of the handling of glucose $\left(r / R, G F R, \mathrm{Tm}_{\mathrm{G}}\right.$, $\mathrm{GFR} / \mathrm{Tm}_{\mathrm{G}}$ ) are technically not open to direct experimental observation and confirmation, it has remained to the present a logical construct based on theoretical extension from certain observations $(2,3)$ : Although not a direct confirmation, as might be found in observations on the kidney by some elaborated form of micropuncture where GFR or $\mathrm{Tm}_{G}$ had a predicted value, the finding of identical quantitative relationships between the structural characteristics of the components of the glucose-handling mechanisms that obtain for their functional behavior adds considerable weight in support of the theory. In part, the confirmation is direct; for example, since $\mathrm{Tm}_{\mathrm{G}}$ $=\mathrm{k} \Sigma \mathrm{pv}$, it may be said that $\mathrm{Tm}_{\mathrm{G}}$ is the measure of the "tubular mass" of the proximal convolutions of the nephrons of a given normal kidney.

Such a quantitative structural-functional correlation makes possible a direct approach to information not available from functional analysisfor example, the observation of glomerulotubular balance in individual nephrons. It has been noted that the relative glomerular activity of a nephron appears to be inversely related to its size, and the question has been posed as to how this may apply to situations involving growth of the renal tissues.

These, and other relationships concerning the nephrons and their totality, the kidney, will become apparent in an examination of the same correlative procedures in the dog, where the structural and functional measurements will be made on the same kidney (25). Moreover, the possible effects of considerable variation in the size of kidneys of different animals and in the relative composition of the kidney in nephrons will afford a more crucial test and an extension of the correlative procedure by means of structuralfunctional equivalents.

\section{v. CONCLUSIONS}

1. A statistical study of the normal human kidney has been made by microdissection to determine the structural dimensions of the parts of the nephron (the glomeruli) through which glucose enters the tubule fluid and of the segments (the proximal convolutions) which remove it.

2. On the basis of this analysis certain structural-functional equivalents have been proposed. When these are substituted in the theoretical functional description of the handling of glucose by the normal kidney and its constituent nephrons, it is possible to calculate such characteristics of renal activity as glomerular activity ( $r$ ) ; total glomerular activity $(\mathrm{R}) ; \mathrm{r} / \mathrm{R}$; glomerular filtration rate (GFR); maximal tubular reabsorption of glucose $\left(\mathrm{Tm}_{\mathrm{G}}\right)$; and $\mathrm{GFR} / \mathrm{Tm}_{\mathrm{G}}$. Within ac- 
cepted limits of observational and statistical error, the values thus calculated from the structural data are identical with those derived from the functional measurements.

3. It is also possible to duplicate in quantitative terms the functional titration curve which describes the over-all process of the handling of glucose by the kidney by means of these structuralfunctional equivalents.

4. The splay in the titration curve of the kidney appears as a result of a certain heterogeneity in the functional activity of its constituent nephrons which correlates quantitatively with the variability of their structural dimensions.

\section{REFERENCES}

1. Walker, A. M., and Oliver, J. Methods for the collection of fluid from single glomeruli and tubules of the mammalian kidney. Amer. J. Physiol. 1941, 134, 562.

2. Walker, A. M., and Bott, P. A.; Oliver, J., and MacDowell, M. C. The collection and analysis of fluid from single nephrons of the mammalian kidney. Amer. J. Physiol. 1941, 134, 580.

3. Shannon, J. A., and Fisher, S. The renal tubular reabsorption of glucose in the normal dog. Amer. J. Physiol. 1938, 122, 765.

4. Smith, H. W., Goldring, W., Chasis, H., Ranges, H. A., and Bradley, S. E. The application of saturation methods to the study of glomerular and tubular function in the human kidney. J. Mt Sinai Hosp. 1943, 10, 59.

5. Mudge, G. H. Clinical patterns of tubular dysfunction. Amer. J. Med. 1958, 24, 785.

6. Wilbrandt, W. Secretion and transport of nonelectrolytes. Symp. Soc. exp. Biol. 1954, 8, 136.

7. Burgen, A. S. V. A theoretical treatment of glucose reabsorption in the kidney. Canad. J. Biochem. 1956, 34, 466.

8. Govaerts, P. Physiopathology of glucose excretion by the human kidney. Brit. med. J. 1952, II, 175.

9. Smith, H. W. Lectures on the Kidney. Lawrence, Univ. of Kansas Press, 1943.
10. Thoma, R. Quoted from Roessle and Roulet (11), p. 64.

11. Roessle, R., and Roulet, F. Mass und Zahl in der Pathologie. Berlin, J. Springer, 1932.

12. Oliver, J., MacDowell, M., and Tracy, A. The pathogenesis of acute renal failure associated with traumatic and toxic injury. Renal ischemia, nephrotoxic damage and the ischemuric episode. J. clin. Invest. 1951, 30, 1307.

13. Sperber, I. Studies on the mammalian kidney. Zool. Bidr. Uppsala 1944, 22, 249.

14. Peter, K. Untersuchungen ueber Bau und Entwicklung der Niere. Jena, G. Fischer, 1909.

15. Pai, H. C. Dissections of nephrons from the human kidney. J. Anat. (Lond.) 1935, 69, 344.

16. Vimtrup, B. On the number, shape, structure, and surface area of the glomeruli in the kidneys of man and mammals. Amer. J. Anat. 1928, 41, 123.

17. Book, M. H. The secreting area of the glomerulus. J. Anat. (Lond.) 1936, 71, 91.

18. Smith, H. W. The Kidney; Structure and Function in Health and Disease. New York, Oxford Univ. Press, 1951.

19. Shannon, J. A., Farber, S., and Troast, L. The measurement of glucose $T m$ in the normal dog. Amer. J. Physiol. 1941, 133, 752.

20. Kittelson, J. A. The postnatal growth of the kidney of the albino rat, with observations on an adult human kidney. Anat. Rec. 1917, 13, 385.

21. Oliver, J. New directions in renal morphology: A method, its results and its future. Harvey Lect. 1944-5, ser. 40, 102.

22. Kolberg, A. Relations of renal tubular and glomerular function as influenced by 75 percent reduction of nephron number; a patho-physiological study. Scand. J. clin. Lab. Invest. 1959, 11, suppl. 41.

23. Trueta, J., Barclay, A. E., Daniel, P. M., Franklin, K. J., and Prichard, M. M. L. Studies of the Renal Circulation. Oxford, Blackwell, 1947.

24. Smith, H. W. Principles of Renal Physiology. New York, Oxford Univ. Press, 1956.

25. Bradley, S. E., Laragh, J. H., Wheeler, H. O., MacDowell, M., and Oliver, J. Correlation of structure and function in the handling of glucose by the nephrons of the canine kidney. J. clin. Invest. 1961, 40, 1113. 